\title{
Die zwei (und mehr) Kulturen des „Klons“
}

\section{Utopie und Fiktion im biowissenschaftlichen Diskurs der Nachkriegszeit ${ }^{1}$}

\section{Christina Brandt}

\begin{abstract}
The Two (and More) Cultures of the "Clone". Utopia and Fiction in Post-War Discourses of Life Sciences
Since the late 1950s, "two cultures" has become a catch phrase for describing a deep divide between science and literature. When Charles P. Snow, who initiated this discussion, introduced the notion of "two cultures" in a lecture at the University in Cambridge in 1959, he referred to an incompatibility of scientific and literary worldviews in Western societies. His thesis of two contradicting cultures immediately received a huge variety of different responses from philosophers, scientists, novelists and literary scholars. However, this article argues that this widespread debate was part of a broader post-war discourse on the impact of modern science on society, in which especially the idea of "scientific progress" was at stake. Central to this debate was the question of how scientific and technological progress could affect the notion of the "human" itself. The paper analyses the emerging discourse on cloning against this background. The constitutive role of fiction and imagination in both fields, science and literature, is explored by tracing the scientific, utopian and literary cultures in which figures of human clones have taken different shapes since the 1960s. At that time, scientists developed utopian views in which the "clone" became a metaphor for future possibilities of transcending and reshaping the human nature. science fiction writers reacted to this by portraying the human clone as an individual and by depicting human clone figures in a psychological way.
\end{abstract}

Keywords: history of 20th century life sciences, two cultures debate, history of the clone concept, science and literature, transhumanism

Schlüsselwörter: Geschichte der Biowissenschaften im 20. Jahrhundert, Zwei-Kulturen-Debatte, Geschichte des Klonbegriffs, Wissenschaft und Literatur, Transhumanismus

1963 veröffentlichte Charles P. Snow einen kurzen Nachtrag zu seiner vieldiskutierten Rede über die „Zwei Kulturen und die wissenschaftliche Revolution“, die er 1959 an der Universität Cambridge gehalten hatte. In diesem Nachtrag ging er überraschenderweise auf die damals noch junge Molekularbiologie ein, indem er ihr eine didaktische Brückenfunktion in seinem Zwei-Kulturen-Szenario zuwies. In seiner Rede vier Jahre zuvor hatte der Physiker und Romancier ${ }^{2}$ das zunehmende Auseinanderfallen zweier vermeintlich getrennter „Kulturen“ - auf der einen Seite Naturwissenschaftler und Techniker, auf der anderen Seite Schriftsteller und die literarisch gebil- 
deten Eliten - diagnostiziert und als wechselseitige Ignoranz zweier Wertesysteme gedeutet, die in der westlichen Welt keinen Ort der gemeinsamen Kommunikation hätten. Während er den Naturwissenschaftlern eine progressive, sozial verantwortliche und politisch engagierte Haltung attestierte, betrachtete er die Schicht der literarisch Gebildeten als eine zutiefst traditionalistische, tendenziell konservative, dem technischen und sozialen Fortschritt gegenüber ignorante Klasse von „Maschinenstürmer[n]“ (Snow 1987a [1959]: 35). Snows Opposition war schematisch und überaus einfach: „Wenn die Naturwissenschaftler die Zukunft im Blut haben, dann reagiert die überkommene Kultur darauf mit dem Wunsch, es gäbe gar keine Zukunft." (Ebd.: 27) $\mathrm{Zu}$ Lasten des naturwissenschaftlich-technischen Selbstverständnisses sah Snow das allgemeine intellektuelle Klima in Großbritannien, wenn nicht gar der gesamten westlichen Welt, jedoch grundlegend durch den antiszientistischen und rückwärtsgewandten Wertekanon der literarischen und geisteswissenschaftlichen Eliten geprägt.

In Erwiderung auf die ersten Kritiken gab Snow 1963 nun seiner Darstellung eine bemerkenswerte Wendung. ${ }^{3}$ Hatte er in der Rede noch die Physiker stellvertretend für die Naturwissenschaftler genannt und als repräsentatives Feld die Thermodynamik verhandelt, so findet sich vier Jahre später die zuvor von ihm mit keinem Wort erwähnte "Molekularbiologie“ in dieser Position. Zu dieser Zeit war es sicherlich nicht ganz überraschend, der Molekularbiologie (eine Bezeichnung, die sich übrigens, wie Snow selbst auch bemerkte, seinerzeit noch keinesfalls eingebürgert hatte) das Potential einer zukünftigen Leitwissenschaft zuzuschreiben. Seit 1961 wurde vielerorts die beginnende biochemische Entzifferung des genetischen Codes als das zukunftsweisende Ereignis für die Genetik des 20. Jahrhunderts thematisiert ${ }^{4}$, und 1962 hatten James Watson, Francis Crick und Maurice Wilkens für die Erforschung der DNA-Struktur den Nobelpreis für Medizin erhalten, was dazu beitrug, dass das Doppelhelix-Modell der DNA einer weiteren Öffentlichkeit bekannt wurde. Erstaunlicher allerdings war die Stellung, die Snow dieser neu heraufziehenden Disziplin zuwies. Aufgrund des visuellen Charakters molekularbiologischer Methoden und aufgrund einer für den Laien leicht zugänglichen Begrifflichkeit nahm er die moderne Biologie als ein Feld wahr, das sich in ein neuartiges interdisziplinäres Modell des Bildungswesens einfügen und damit vielleicht zum didaktischen Brückenschlag zwischen den Kulturen auffordern könne. ${ }^{5}$ Vor allem beobachtete Snow mit den modernen Biowissenschaften den Anfang einer neuen wissenschaftlichen Revolution, „die so unmittelbar den Menschen aus Fleisch und Blut" betreffe (Snow 1987b [1963]: 76). Darin sah er den Hauptgrund, warum dieses neue Wissenschaftsfeld an der Schnittstelle von Naturwissenschaft und literarisch-intellektueller Reflexion anzusiedeln sei. Dieses neue „Gebiet der Naturwissenschaften“, welches "das menschliche Selbstverständnis entscheidender beeinflussen“ werde „als jeder wis- 
senschaftliche Fortschritt seit Darwin“ (ebd.: 75), ziele nunmehr zentral auf die Veränderung grundlegender anthropologischer Kategorien. Dies allein sei schon Begründung genug, dass Künstler und Intellektuelle sich mit dem Feld beschäftigen müssten. Nicht mehr die industrielle Revolution, also die technische Anwendung naturwissenschaftlichen Wissens im Zuge einer alle Gesellschaftsbereiche befördernden Industrialisierung (worauf sich Snows ungetrübtes Fortschritts-Plädoyer ein paar Jahre zuvor gegründet hatte), war nunmehr für ihn der entscheidende Punkt seiner Bewertung, sondern eine durch die Biowissenschaften sich anbahnende anthropologische und soziale „Revolution“. 6 Mit seiner Einschätzung war Snow zu Beginn der 1960er Jahre gewiss nicht allein. Sie bringt vielmehr zum Ausdruck, dass zu dieser Zeit zwei wesentliche Elemente im naturwissenschaftlich-gesellschaftlichen Koordinatensystem neu verhandelt wurden: die Frage nach den Auswirkungen des wissenschaftlichen Fortschritts auf die Gesellschaft der Zukunft sowie das allmähliche Auftauchen eines neuen naturwissenschaftlichen Feldes, das einen bis dato unbekannten, manipulativen Zugang zur Natur des Menschen verhieß und damit zu einem neuen diskussionsbedürftigen Machtfaktor neben Atomphysik und Kybernetik wurde.

\section{Die Zwei-Kulturen-Debatte als Symptom der Nachkriegszeit. Naturwissenschaftlicher „Fortschritt" und die Frage nach der Zukunft des Humanen}

Statt Snows Zwei-Kulturen-These und ihre Rezeption ein weiteres Mal kritisch zu hinterfragen, ${ }^{7}$ wird sie hier selbst als Symptom eines historischen Umbruchs in der Nachkriegszeit betrachtet, in der sich in der gesellschaftlichen Auseinandersetzung mit Naturwissenschaft und Technik zentrale Wertefragen neu ausrichteten. Snows These wurde bekanntlich in der Folgezeit zum heftig debattierten Schlagwort für eine vermeintliche Trennungsbewegung, in der zwei Wissenschaftsordnungen - eine naturwissenschaftliche und eine geisteswissenschaftliche - mit ihrer Methodik und in ihrem Selbstverständnis einander gegenüberstehen. In dieser Rezeption geht dabei nicht nur unter, dass Snows überpointierte Rhetorik vorrangig der Forderung nach einer Reform eines verkrusteten britischen Bildungssystems geschuldet war. Auch wird allzu schnell dabei übersehen, dass die von Snow ausgelöste, unmittelbare Auseinandersetzung weder primär eine Methodenkontroverse über das Verhältnis von empirischer Forschung einerseits oder geisteswissenschaftlicher Interpretation andererseits war, noch war sie eine erkenntnistheoretische Debatte über das (vor allem im deutschsprachigen Raum diskutierte) Verhältnis von Geistes- und Naturwissenschaften. Zwar finden sich auch diese Elemente in der Auseinandersetzung zu Beginn der 1960er Jahre auf die eine oder andere Art wieder. Zu nennen ist hier vor allem 
die um einen Ausgleich zwischen Snow und dem Literaturtheoretiker Frank Leavis bemühte Intervention des Schriftstellers Aldous Huxley, der 1963 mit Literature and Science ein ganzes Buch zur Kontroverse veröffentlichte. Darin stellte Huxley einen Katalog zentraler Differenzen von Wissenschaft und Literatur auf und betonte deren Eigenständigkeiten. Zugleich sah er aber auch eine Funktion der Literatur darin, dass sie eine Vermittlungs- oder Übersetzungsrolle übernehmen könne, sei es, um die abstrakten naturwissenschaftlichen Befunde mit der alltäglichen Erfahrungswelt zu versöhnen oder sei es, um auf ethisch fragwürdige Verwendungsweisen naturwissenschaftlicher Erkenntnisse aufmerksam zu machen. ${ }^{8}$

Jedoch war die Kluft zwischen den Kulturen als Konsequenz einer zunehmenden disziplinären Ausdifferenzierung von Wissensfeldern nur ein vordergründiges Problem. Vor allem war die Zwei-Kulturen-Debatte zu Beginn der 1960er Jahre eine Wertedebatte, in der sich grundlegende Verunsicherungen bezüglich der gesellschaftlichen Konsequenzen der Naturwissenschaften und Technik in der Nachkriegszeit spiegelten. Aufgrund der historischen Erfahrung von Holocaust und Zweitem Weltkrieg und im zeitgenössischen Kontext der atomaren Bedrohung des Kalten Krieges war die Frage nach der gesellschaftlichen Verantwortung sowohl der Naturwissenschaftler als auch der Geisteswissenschaftler aufgeworfen. ${ }^{9}$ Im Zentrum der Auseinandersetzung stand dabei die Einschätzung des naturwissenschaftlichen Fortschritts und seiner technischen, sozialen und politischen Konsequenzen. Dass Snow damit einen, wie er selbst irritiert bemerkte, „Nerv“ der Zeit (Snow 1987b [1963]: 60) getroffen hatte, zeigt sich auch in den unmittelbaren Reaktionen. Während bei Snow der Begriff des „Fortschritts“ eindimensional konzipiert und uneingeschränkt positiv konnotiert war, konstatierte der Physiker Robert Oppenheimer, der sich 1962 in die Zwei-Kulturen-Debatte einschaltete, wesentlich pessimistischer das Auseinanderfallen von wissenschaftlichem und moralischem Fortschritt und forderte angesichts der Unwiderruflichkeit der durch naturwissenschaftliche Erkenntnisse einmal in Gang gesetzten weltverändernden Auswirkungen das Engagement einer "Gemeinschaft der Intellektuellen" (Oppenheimer 1987 [1962]: 164). Der Literaturwissenschaftler Martin Green sprach 1964 angesichts des atomaren Zerstörungspotentials sogar vom "Antihumanismus der Naturwissenschaften“ (Green 1987 [1964]: 139). Es war schließlich Jürgen Habermas, der diese Dimension der Debatte 1966 auf den Punkt brachte. Er transferierte die Frage nach der Kluft zwischen den „zwei Kulturen“, die Snow als individuelles Bildungsdefizit und als gesellschaftliches Werteproblem behandelt hatte, in die techniksoziale Problemstellung, wie eine den Menschen entfremdete, sich verselbständigende und ungestüm entwickelnde Technik in eine demokratische Auseinandersetzung eingebunden und in einen gesellschaftlichen Konsensus zurückgeholt werden könne (vgl. Habermas 1987 [1966]: 320). Mit Blick auf das von Aldous Huxley vorgeschlagene Modell einer literarischen Vermitt- 
lung zwischen naturwissenschaftlichen Theoriesystemen und alltäglicher Lebenswelt konterte Habermas polemisch, die „Vorstellung einer hypothesenverarbeitenden Atomdichtung" gehe von "falschen Voraussetzungen aus" (ebd.: 315). ${ }^{10}$ Er sah die Kluft zwischen den Kulturen nicht lediglich als ein Übersetzungsproblem zwischen Wissenschaft und Literatur, sondern wesentlich grundlegender als politisches Kommunikationsproblem. Denn, so Habermas,

„[j]enes Missverhältnis der beiden Kulturen ist nur deshalb so beunruhigend, weil sich in dem scheinbaren Streit zweier konkurrierender Geistestraditionen in Wahrheit ein Lebensproblem der verwissenschaftlichten Zivilisation abzeichnet: wie nämlich die heute noch naturwüchsige Beziehung zwischen technischem Fortschritt und sozialer Lebenswelt reflektiert und unter die Kontrolle einer rationalen Auseinandersetzung gebracht werden kann." (Habermas 1987 [1966]: 315)

Die Diskussion über die „zwei Kulturen“, die zu Beginn der 1960er Jahre einsetzte, lässt sich gewiss auch als Element einer letztlich vielleicht bis in die Antike zurückzuverfolgenden Trennungsgeschichte begreifen, in der es vielfältige Versuche gab, die Poesie von einem der "Wahrheit" verpflichteten Wissen abzugrenzen. ${ }^{11}$ Im unmittelbaren zeithistorischen Kontext betrachtet verdeutlicht sich in der Debatte um Snow jedoch vor allem eins: eine in den 1960er Jahren erneut (und verstärkt) einsetzende kritische Bewertung des wissenschaftlichen Fortschritts und seiner sozialen und anthropologischen Konsequenzen.

\section{Die Figur des Klons. Wissenschaftskulturen und Klonfiktionen}

Im Folgenden untersuche ich die in den 1960er Jahren einsetzende Kontroverse zu den zukünftigen gesellschaftlichen Folgen der modernen Biowissenschaften und ihren Auswirkungen auf den Menschen. Im Fokus steht dabei die sich zu dieser Zeit erstmals abzeichnende biotechnische Möglichkeit des Klonens von tierischen Organismen und die damit einsetzende Diskussion über zukünftig womöglich herstellbare Menschenklone. Diese Schwerpunktsetzung bietet sich an, weil in dem entstehenden Klondiskurs in aller Deutlichkeit zum Ausdruck kam, was auch in der Zwei-Kulturen-Debatte verhandelt wurde: die sich neu konfigurierende Wertediskussion über wissenschaftlichen Fortschritt und soziale Lebenswelt, die Auseinandersetzung über die Bedingungen der menschlichen Existenz in einer hochtechnisierten Welt und nicht zuletzt die Problematik, wem die Deutungsmacht über das Humane zukommt. In der Tat trafen hier die von Snow konstatierten Kulturen aufeinander, allerdings in leicht anderer Weise als von Snow diskutiert. Denn eine Facette der Zwei-Kulturen-Debatte, nämlich die vermeintliche Kluft zwischen literarisch-fiktiver und wissenschaftlich-faktischer Sphäre, lässt sich am Beispiel der Klon-Thematik kritisch hinterfragen. Als Zu- 
kunftsphantasma war der „Klon“ in den 1960er und 1970er Jahren sowohl biowissenschaftliche als auch literarische Fiktion. Wie noch zu sehen sein wird, war er sowohl Produkt konkreter, experimenteller Forschungen als auch das Resultat einer Reihe von semantischen Verschiebungen und begrifflichen Neubesetzungen. ${ }^{12}$ Vor allem wurde die Figur des Menschenklons in diesen zwei Jahrzehnten zu einem Symbol für die neue, auch von Snow erwähnte in Gang befindliche biowissenschaftliche Revolution. Anhand der Klon-Thematik wurden die möglichen Auswirkungen gentechnischer und biomedizinischer Forschung auf das Selbstverständnis des Menschen fiktiv durchgespielt. Auch wenn sich die Science Fiction der 1970er Jahre durchaus in andere Richtungen entwickelte, als Aldous Huxley es 1932 in seinem Roman Brave New World vorgeschlagen hatte, erfüllten einige Autorinnen und Autoren durchaus jene Forderung, die er später im Kontext der ZweiKulturen-Debatte an Literatur gestellt hatte: nämlich die literarische Verarbeitung ethisch fragwürdiger Felder naturwissenschaftlicher Erkenntnisse, die direkt den Menschen betreffen (vgl. A. Huxley 1963: 101).

Allerdings war die fiktionale Ausgestaltung des Klonthemas keineswegs den Schriftstellern vorbehalten. Im Gegenteil, zunächst waren es die utopischen Entwürfe prominenter Biowissenschaftler, die seit Anfang der 1960er Jahre wesentlich dazu beitrugen, die Figur des menschlichen Klons als Zukunftsvision zu etablieren. Hier ist gleichermaßen nach der diskursiven Funktion dieser literarisch-poetischen und der wissenschafts-imaginativen Entwürfe zu fragen - und dies nicht nur in Bezug darauf, in welchem Verhältnis die fiktiven Versuche zu den tatsächlich durchgeführten Klonexperimenten stehen. Neben der Frage, welche Formen des Wissens in den fiktiven Szenarien reflektiert wurden, ist hier vor allem von Interesse, welche Möglichkeitsräume durch sie überhaupt erst eröffnet und welche zukünftig möglichen Handlungsfelder bereitgestellt wurden. In zweierlei Hinsicht wird damit die Frage nach den „Wissenschaftskulturen“ neu aufgeworfen: Zum einen wird dargelegt, dass die fiktive Imagination nicht nur im Bereich der Science Fiction eine Rolle spielt, sondern dass Fiktion und der imaginative Entwurf möglicher Welten ebenso ein fester Bestandteil der Wissenschaft ist. ${ }^{13}$ Auch in den Biowissenschaften des 20. Jahrhunderts gibt es, wie weiter unten gezeigt wird, eine anhaltende Tradition der utopischen Entwürfe, die beides bereitstellt: einen fiktiven Raum zur Auslotung biopolitischer Möglichkeiten und narrative Muster, die eine bestimmte biowissenschaftliche Weltsicht und damit auch eine immer wieder aktualisierbare, sinnstiftende Ordnung erzeugen. Zum anderen gilt es, die vermeintlichen „zwei Kulturen“ in Richtung mehrerer „Kulturen“ (im Sinne von tradierten Forschungs- und Wissensfeldern) zu öffnen, denn deutlich wird, dass die Biowissenschaften selbst aus einer Vielzahl verschiedener Experimentalkulturen bestehen. Die utopische Tradition der Formulierung biopolitischer Visionen stellte nur eine von mehreren Wissenskulturen dar und hatte keine unmittelbare er- 
kenntnisleitende Funktion für die experimentelle Klonforschung, die durch ihre eigene Form der Dynamik vorangetrieben wurde.

Im Folgenden werden zunächst die biowissenschaftlichen Experimentalentwicklungen der Klonforschung an Fröschen seit den späten 1950er Jahren skizziert, die mit leichter zeitlicher Verzögerung seit Mitte der 1960er Jahre öffentliche Resonanz gefunden hatten. Die Projektionen der Klonversuche am Menschen entwickelten sich zwar aus dieser spezifischen biowissenschaftlichen Forschungslandschaft heraus, die Phantasmen der künstlichen Menschenschöpfung oder die Visionen zur Kontrolle der Reproduktion sind gleichwohl kulturhistorisch wesentlich älter. Anschließend wird die Entstehung der Klonfigur in den biopolitischen Utopien der 1960er Jahre thematisiert. Diskutiert werden diese Wissenschaftsfiktionen im Hinblick auf ihre Wurzeln im eugenischen Diskurs der 1920er und 1930er Jahre. Was aber sagen die Klon-Fiktionen der 1960er und 1970er Jahre über die Grenzziehungen des Humanen angesichts einer biotechnologisch geprägten Welt aus? Der abschließende Teil ist der Analyse der Klonthematik in der Science Fiction seit Ende der 1960er Jahre gewidmet. Es geht darin um die diskursiven Funktionen dieser literarischen Auseinandersetzung.

\section{Tier-Klone im Labor. Zellkern-Transplantationsexperimente in den 1960er Jahren und ihr Forschungskontext}

Im Juli 1958, ein Jahr bevor Snow seinen Vortrag in Cambridge hielt, veröffentlichte eine Forschergruppe um Michael Fischberg an der Universität Oxford eine kurze, einseitige Notiz im Journal Nature mit dem Titel: „Sexually Mature Individuals of Xenopus laevis from the Transplantation of Single Somatic Nuclei“. Die Autoren - neben Fischberg waren dies sein Doktorand John Gurdon und sein Mitarbeiter Thomas Elsdale - beschrieben, dass die Transplantation von Zellkernen aus Zellen des sich entwickelnden FroschEmbryos in unbefruchtete Frosch-Eizellen dazu führte, dass eine normale Embryonalentwicklung in Gang gesetzt wurde (Gurdon/Elsdale/Fischberg 1958). Fischbergs Gruppe arbeitete mit dem südafrikanischen Krallenfrosch Xenopus laevis. Ähnliche Versuche waren bereits einige Jahre zuvor an einer anderen Froschart (nämlich dem nordamerikanischen Leopardfrosch Rana pipiens) von Robert Briggs und Thomas King am Krebsforschungsinstitut in Philadelphia durchgeführt worden (vgl. Briggs/King 1952, King/Briggs 1956). Während die Gruppe in Philadelphia jedoch festgestellt hatte, dass Zellkerne, die aus einem späten Entwicklungsstadium des Frosch-Embryos stammten, nach ihrer Transplantation in eine (zuvor entkernte) Eizelle nicht mehr in der Lage waren, eine normale Embryonalentwicklung zu induzieren, berichteten die Wissenschaftler aus Oxford, dass es ihnen sogar gelungen sei, durch den Transfer von Zellkernen aus sehr späten Embryonalstadien 
normale Entwicklungsprozesse zu stimulieren. Die Oxforder Gruppe veröffentlichte 1958, dass aus dieser Art des Zellkerntransfers Entwicklungen bis hin zu geschlechtsreifen Fröschen möglich seien. Einige Jahre später, 1966, sprachen John Gurdon und seine damalige Kooperationspartnerin aus Genf Verena Uehlinger sogar von „fruchtbaren Zellkernen“ aus Darmzellen. ${ }^{14}$

Die Artikel der Forschergruppen in Philadelphia und Oxford aus den 1950er Jahren stehen am Anfang einer Reihe von Arbeiten, die aus heutiger Perspektive den Beginn der organismischen Klonforschung im engeren Sinne markieren. ${ }^{15}$ Zeitgenössisch fand diese Forschung, die sich mit ihrem Transplantationsansatz noch gänzlich in einer embryologischen Tradition bewegte, zunächst jedoch kaum größere öffentliche Beachtung. Nur einige Wissenschaftler, die für ihre visionären und provozierenden Aussagen in der Öffentlichkeit bekannt waren, so insbesondere der Genetiker Hermann J. Muller und der Molekularbiologe Joshua Lederberg, diskutierten bereits sehr früh, nämlich seit Ende der 1950er Jahre, die wissenschaftlichtechnischen Zukunftspotentiale und möglichen gesellschaftlichen Anwendungen der Experimente, worauf ich weiter unten noch ausführlich zurückkommen werde. Insgesamt blieben die Arbeiten zum Zellkerntransfer jedoch auch innerhalb eines größeren Fachpublikums bis Mitte der 1960er Jahre ohne weitergehende Resonanz. Inwieweit hierbei eine Rolle spielte, dass die Ergebnisse von Gurdon, dem erstmals das Klonen ausgewachsener Frösche über somatischen Zellkerntransfer gelang, zunächst umstritten waren, kann hier nur spekuliert werden. Gurdon hatte Anfang der 1960er Jahre die Position seines Doktorvaters Fischberg (der für eine Stelle in Genf in die Schweiz zurückgekehrt war) an der Universität Oxford übernommen und die Zellkerntransfer-Arbeiten mit einer neuen Forschergruppe fortgesetzt (vgl. Gurdon 2006).

Ob sich der Zellkern selbst während der Embryonalentwicklung veränderte und wie sich das Verhältnis zwischen Zellkern und Cytoplasma während des Prozesses der Zelldifferenzierung gestaltete, waren grundlegende Fragen, welche die Embryologen seit Ende des 19. Jahrhunderts beschäftigt hatten (und die von den Wissenschaftlern auch in den 1950er Jahren noch bis auf August Weismanns Spekulationen über erbungleiche Teilungen zurückgeführt wurden). Die Resultate aus Oxford legten nun nahe, dass sich der Zellkern auch nach der Ausdifferenzierung nicht verändert, sondern dass seine "genetische Information“ komplett erhalten bleibt, wie auch der Embryologe Gurdon gemäß dem neuen molekularbiologischen Informationsdiskurs bereits 1962 formulierte. ${ }^{16}$ Damit setzte sich Gurdon deutlich von den Auffassungen seiner Kollegen Briggs und King ab. Die beiden Wissenschaftler, die in den 1950er Jahren die entscheidenden Techniken des Zellkerntransfers entwickelt hatten, hatten aus den von ihnen beobachteten abnormalen Embryonalentwicklungen gefolgert, dass der Zellkern sich im Zuge der Zelldifferenzierung während der Embryonalentwicklung selbst irrever- 
sibel verändert. Diese Diskrepanz der Ergebnisse und vor allem die unterschiedliche Einschätzung, inwieweit die von Gurdon konstatierte Totipotenz ausdifferenzierter Zellkerne durch seine Experimente eindeutig nachweisbar war, überschattete eine Zeitlang das Verhältnis zwischen Gurdon und seinen amerikanischen Kolleginnen und Kollegen. ${ }^{17}$ Diese Situation sowie die Tatsache, dass nur ein geringfügiger Anteil der von Gurdon durchgeführten Zellkerntransfers erfolgreich war, führte dazu, dass die Klon-Forschungen an Fröschen innerhalb der embryologischen Fachgemeinschaft zunächst durchaus differenzierter betrachtet wurden als ihre (zeitlich versetzte) öffentliche Rezeption vermuten lässt.

Auch wenn die Experimente erst vergleichsweise spät, nämlich rund ein Jahrzehnt nach den ersten Publikationen, von einer größeren Öffentlichkeit wahrgenommen und diskutiert wurden, entwickelten sich die Phantasmen des Klonens im öffentlichen Raum wesentlich früher. Szenarien der Multiplikation von Organismen durch Techniken, die beim Embryo und bei der Kontrolle der Reproduktion ansetzten (gleichwohl noch nicht mit dem Begriff des „Klonens“ belegt), waren prominent seit Aldous Huxleys Brave New World. Diese Science Fiction war selbst Ausdruck eines sich in den 1920er und 1930er Jahren neu herausbildenden Diskurses der Reproduktionsbiologie. Für das neue Feld, das Impulse aus verschiedenen Forschungsströmungen (wie Hormonforschung, landwirtschaftliche Züchtungsforschung, medizinische Physiologie, Zellkulturtechniken und Embryologie) erhalten hatte und das sich in den ersten Jahrzehnten des 20. Jahrhunderts allmählich etablierte, war nicht nur das Erscheinen eines neuen Forschungsobjekts Fortpflanzung und deren Kontrolle - charakteristisch. Sondern vor allem gründete es sich auf ein Ingenieursideal, das seit dem Beginn des Jahrhunderts die Biologie in neuer Weise prägte. ${ }^{18}$ Hier knüpften die biowissenschaftlichen Klonvisionen der 1960er Jahre zunächst an. Für Wissenschaftler wie Muller und Lederberg versprach die Forschung zum Zellkerntransfer diesen Visionen neue und vor allem konkrete technische Realisierungsmöglichkeiten zu geben. Briggs, King und Gurdon selbst allerdings bewegten sich mit ihren embryologischen Forschungsarbeiten nicht in dieser Tradition reproduktionsbiologischer Forschung. Vielmehr war die frühe Forschung zum Zellkerntransfer in einem Feld angesiedelt, dessen Interesse auf grundlegende Fragen der Differenzierung von Zellen ausgerichtet war. Eine unmittelbare medizinische, züchterische oder in anderer Hinsicht anwendungsorientierte Zielrichtung, wie sie die Reproduktionsbiologie auszeichnete, wiesen diese Arbeiten zunächst nicht auf. Die Technik des Zellkerntransfers und damit auch die geklonten Frösche waren nicht Ziel, sondern Werkzeug einer Forschung, die zunächst den grundlegenden Mechanismen der Differenzierung und der Frage nach der Stabilität des Genoms in ausdifferenzierten Zellen nachging. Diese Fragestellung verschob sich im Verlauf der 1960er Jahre vor dem Hintergrund molekularbiologischer Theoriebildung zunehmend 
in Richtung der Problematik von Regulationsmechanismen der Genaktivierung. Anders formuliert: Die Zellkerntransferarbeiten an Fröschen (und ihr Nebenprodukt, nämlich die Möglichkeit, vermeintlich identische Organismen im Labor herzustellen) trafen auf einen wesentlich weiter zurückreichenden biopolitischen Diskurs.

Im Verlauf der 1960er Jahre gingen jedoch die Entwicklung der Experimentaltechniken und die historisch wesentlich älteren Visionen von der Manipulation der Reproduktion eine Art diskursive, strukturelle Kopplung ein. Was aus dieser Konjunktur, dem unerwarteten Zusammentreffen zunächst getrennter Forschungsfelder und diskursiver Entwicklungslinien ${ }^{19}$, hervorging, war ein Repräsentationsraum, der einen neuen Rahmen für die Debatten bereitstellte: In den 1970er Jahren, der Hochphase einer ersten weiträumigen Diskussion zum Klonen, avancierten Darstellungen von Gurdons seriell geklonten Fröschen (Abbildungen, die 1962 noch für keinerlei Aufsehen gesorgt hatten) zu einem medial vielfältig inszenierten Symbol für eine neue, auch die Kategorie des Humanen herausfordernde Macht der modernen Wissenschaften vom Leben. Gurdon, der mittlerweile an der Universität Cambridge seinen Forschungsansatz als ein In-vivo-System zur Erforschung der Genexpression und Regulation etabliert hatte, entwickelte selbst zu dieser Zeit erste Theorien zu Fragen der sogenannten „Reprogrammierung" des Zellkerns (Gurdon u.a. 1979). Wenn hier, in der konkreten Forschung, über die Experimentalbefunde hinausgehende Visionen oder kulturell wirkmächtige Narrative eine Rolle spielten, dann waren es nicht solche der technischen Vervielfältigung (wie in so manchen Klonphantasmen der Zeit), sondern es war die kybernetisch inspirierte Vorstellung des zeitlichen ,Zurücksetzens' des genetischen Programms.

In den 1970er Jahren wurde versucht, die Techniken des somatischen Zellkerntransfers, die an Amphibien entwickelt wurden, auch auf Säugetiere zu übertragen. Derek Bromhall, ein Doktorand Gurdons, arbeitete beispielsweise an Verfahren des Zellkerntransfers bei Kaninchen (vgl. Bromhall 1975). Obwohl sie an einem klassischen und etablierten Forschungsobjekt der Reproduktionsbiologie, dem Ei des Kaninchens, durchgeführt wurde, blieb diese Forschung letztlich jedoch erfolglos. Auch die Versuche, Klontechniken an Mäusen zu entwickeln, scheiterten zunächst. Das von dem Mediziner und Molekularbiologen Karl Illmensee gegen Ende des Jahrzehnts behauptete erfolgreiche Klonen von Mäusen stellte sich schließlich als ein wissenschaftlicher Betrugsfall dar (Illmensee/Hoppe 1981)..$^{20}$

Darüber hinaus beeinflussten zwei weitere Forschungsfelder die Debatte zum Klonen nachhaltig, die mit den Arbeiten zum Zellkerntransfer jedoch nichts zu tun hatten: die molekularbiologischen Entwicklungen in der rekombinanten DNA-Technologie (das sogenannte gene cloning als Vervielfältigung von DNA-Abschnitten) sowie die medizinischen Forschungen zur In-vitro-Fertilisation. Die öffentliche Diskussion zu Gentechnik und Repro- 
duktionsmedizin erreichte während der zweiten Hälfte der 1970er Jahre ihren Höhepunkt. Die Konferenz von Asilomar 1975 und die höchst kontrovers diskutierte Geburt des in den Medien so bezeichneten ersten „Retortenbabys“ 1978 markieren hier bedeutsame historische Einschnitte. Die Klondebatte erfuhr damit eine erste vorläufige Zuspitzung. Die Auseinandersetzung über den biowissenschaftlichen Fortschritt und seine sozialen und anthropologischen Folgen begann aber weitaus früher.

\section{Von der „Biology Fiction” zur literarischen Fiktion. Klon- Utopien im Kontext von Eugenik und Reproduktionsbiologie}

"Sie ähneln in mancher Hinsicht einem utopischen Roman, der ja bekanntlich auch an bestimmten wissenschaftlich gesicherten Gegebenheiten anknüpft, um dann der Phantasie ein schrankenloses Feld der Betätigung zu gewähren“, formulierte ein Rezensent 1952 zu den populärwissenschaftlichen Ausführungen des französischen Embryologen Jean Rostand (Küchenhoff 1952: 910). Dessen Buch Die Biologie und der Mensch der Zukunft, das gerade ins Deutsche übersetzt worden war, versprach unter Bezugnahme auf embryologische und physiologische Forschungen der ersten Jahrzehnte des 20. Jahrhunderts zukünftige Manipulationsmöglichkeiten einer auf die Reproduktion zielenden Biotechnik. Neben parthenogenetischer Fortpflanzung, Androgenesis und künstlicher Zwillingsbildung mittels Splitting des Embryos wurden von Rostand hier weitere Zukunftsvisionen der gelenkten Mutation, der Schwangerschaft in der Retorte und der Züchtung des Übermenschen für die nicht allzu ferne Zukunft in Aussicht gestellt. Dass die "'biology fiction' oft kaum von methodischen Forschungszielen zu trennen“ sei, bemerkte eineinhalb Jahrzehnte später auch Friedrich Wagner (1969: 8). Der im deutschsprachigen Raum seinerzeit meist zitierte Kritiker biowissenschaftlicher Entwicklungen bezog sich dabei vor allem auf programmatische Statements englischsprachiger Wissenschaftler wie Haldane, Muller, Julian Huxley und Lederberg.

In der Tat entwickelten diese Wissenschaftler im Verlauf der 1950er und 1960er Jahre Wissenschaftsutopien, die durchaus Snows Vorstellung, „dass die Naturwissenschaftler die Zukunft im Blut" (Snow 1987a [1959]: 27) hätten, bestätigen könnten. Rostand, Muller, Haldane und Julian Huxley gehörten einer Generation an, die durch den eugenischen, embryologischen und evolutionstheoretischen Diskurs zu Beginn des 20. Jahrhunderts geprägt wurde. Sie entwarfen Zukunfts- und vor allem Fortschrittszenarien, die durchaus jene Charakteristika erfüllten, die gemeinhin der Science Fiction zugeschrieben werden: Auch sie stellten einen fiktiven Vorgriff auf die Zukunft dar, der von der Annahme getrieben war, dass die gesellschaftliche und menschliche Zukunft per se eine technische Zukunft sei, und sie lassen das Bestreben er- 
kennen, das gesellschaftlich Utopische, das „Unausdenkbare technisch oder vielmehr pseudotechnisch zu plausibilisieren“" (Stierle 2001: 423).

\section{Utopien der Reproduktion in den 1920er und 1930er Jahren: Haldane und Muller}

Es ist sicherlich kein Zufall, dass insbesondere Muller und Haldane die Idee des Klonens mittels Zellkerntransfers in den 1960er Jahren in die Debatten über die Möglichkeiten einer biotechnisch geprägten Zukunft neu einbrachten. Beide Wissenschaftler hatten bereits in den 1920er und 1930er Jahren Wissenschaftsfiktionen entworfen, in denen die Kontrolle der Reproduktion und die Entkopplung der Fortpflanzung vom menschlichen Organismus zentrale Bestandteile waren. 1924 war der britische Evolutionstheoretiker Haldane mit der Veröffentlichung seiner kleinen Abhandlung Daedalus or Science and the Future als Zukunftsvisionär in Erscheinung getreten. Nicht ungewöhnlich für den eugenischen Zeitgeist der 1920er Jahre hatte Haldane die Biowissenschaften und die Medizin als die zukünftigen Leitwissenschaften des Jahrhunderts gesehen. Sie würden, so der visionäre Blick, in dieser Funktion die Physik und Chemie ablösen, gerade weil die Wissenschaften vom Leben ein enormes, auch politisches Anwendungspotential mit sich brachten. Haldane imaginierte im Daedalus erstmals die Entwicklung von Embryonen außerhalb des Frauenkörpers, wofür er den Begriff der „Ektogenese“ erfand (Haldane 1925). Seine Zukunftsentwürfe waren im Stil einer utopischen Erzählung angelegt und stellten die imaginierten wissenschaftlichen Entwicklungen aus der Perspektive eines aus dem 21. Jahrhundert rückblickenden Erzählers dar. Wie schon oft hervorgehoben wurde, inspirierten diese fiktiven Entwürfe Haldanes langjährigen Freund Aldous Huxley beim Schreiben seines Romans Brave New World. ${ }^{21}$

Auch Muller, der 1946 den Nobelpreis für seine in den 1920er Jahren die Strahlengenetik begründende Forschung an Drosophila-Mutanten erhalten hatte, war Autor einer Wissenschaftsutopie: In Out of the night. A biologist's view of the future (1935 veröffentlicht, aber bereits in den 1920er Jahren in Grundzügen verfasst ${ }^{22}$ ) zeichnete Muller zukünftige Linien einer an sozialistischen Idealen orientierten Genetik und Eugenik. Unter Eugenik verstand er die soziale Richtungsweisung der menschlichen biologischen Evolution (vgl. Muller 1935: 44). In seinem Plädoyer einer zukünftigen Eugenik berief er sich auf die marxsche Auffassung, dass technische Veränderungen der Produktion zu veränderten Produktionsverhältnissen und damit letztlich auch zu grundlegenden Veränderungen gesellschaftlicher und sozialer Verhältnisse führen. In Analogie dazu ging Muller davon aus, dass neue Biotechniken, etwa die von ihm ins Zentrum gestellte Technik der künstlichen Befruchtung, zu Veränderungen der Reproduktionsverhältnisse und damit letztlich 
zu einem Wandel sozialer und gesellschaftlicher Institutionen wie der Ehe oder den tradierten Geschlechterrollen führten (vgl. ebd.: 117).

Dass Muller Zeit seines Lebens Befürworter einer sogenannten positiven Eugenik war, ist hinlänglich bekannt (vgl. Pauly 1987: 177-189, Carlson 1995). Interessanter ist in diesem Zusammenhang, auf welche technischen Entwicklungen sich seine Zukunftsvisionen in den 1920er und 1930er Jahren gründeten. Die strahlenbiologischen Versuche an Mutanten der Drosophila hatten verdeutlicht, dass es in der Genetik nicht nur möglich ist, biologische Objekte durch Kreuzung und Züchtung je nach Bedarf im Labor herzustellen, sondern sie hatten - noch einen Schritt weitergehend - auch gezeigt, dass diese Prozesse durch die Anwendung von Röntgenstrahlen wesentlich beschleunigt werden konnten. Vor allem aber waren es embryologische und zellbiologische Techniken, die Muller als zukunftsweisend ansah. Er sprach bereits 1935 davon, dass die Forschung am "plastischen Embryo“ (Muller 1935: 73) wegweisend sein könne in Bezug auf die zukünftigen Möglichkeiten, die Reproduktion derart zu beeinflussen, dass sie insgesamt zu einer Verbesserung des Genpools führt. Dabei dachte er weniger an Eingriffe in die individuelle Embryonalentwicklung als vielmehr an Techniken, die sich aus der embryologisch-zellbiologischen Forschung weiterentwickeln ließen, etwa die Haltung von Organen in vitro (insbesondere von Eierstöcken, woran Alexis Carell, einer der Begründer der Zellkulturtechniken, Anfang der 1930er Jahre arbeitete und worauf Muller sich auch explizit bezog), oder die Züchtung von Hodengewebe im Reagenzglas. Da für Muller die künstliche Befruchtung eine zukünftige eugenische Schlüsselstellung einnahm, sah er gerade in Letzterem ein potentiell unerschöpfliches Reservoir zur Produktion von Spendersperma ausgewählter, in ihrem gesellschaftlichen Engagement oder in ihren intellektuellen Fähigkeiten herausragender Persönlichkeiten.

Was sagen solche wissenschaftlichen Utopien oder Wissenschaftsfiktionen aus? Dass Utopien konstitutiv sind für ein sich neu etablierendes Forschungsfeld, jedoch nach gelungener Etablierung verleugnet werden, hat Peter Weingart schon vor Jahren hervorgehoben (vgl. Weingart 1984: 173f.). Eine der diskursiven Hauptfunktionen von wissenschaftlichen Utopien sieht er darin, dass sie als Verbindungselement zwischen den kognitiven Forschungsbestrebungen in einem Wissenschaftsfeld und dessen sozialen Anwendungsmöglichkeiten (etwa institutionelle Neuorganisationen oder die Neudefinition von sozialen Werten) fungieren. Weingart spricht bezüglich der Wissenschaftsutopien von „scientification“, um auszudrücken, dass sie Elemente einer größeren, das 20. Jahrhundert grundlegend prägenden Rationalisierungstendenz sind. In dieser kommt zum Ausdruck, was auch das wissenschaftliche Selbstverständnis prägt: der Glaube an die Beherrschbarkeit und Kontrolle wissenschaftlicher und technischer Wissensproduktion und das Ausblenden möglicher, nichtkalkulierbarer Widerständigkeiten. Neben diesem Aspekt, in dem sich vor allem eine bestimmte Wissenschafts- 
auffassung ausdrückt, lässt sich darüber hinaus argumentieren, dass es gerade die narrative Struktur und der fiktive Entwurf solcher Utopien sind, die ihren begründenden Status ermöglichen. Wie literarische Fiktionen spielen diese Wissenschaftsfiktionen nicht nur mit Sprache und kreieren neue, mögliche Welten - so ist beispielsweise die Neuschöpfung von Begriffen ein nicht zu unterschätzendes Charakteristikum. Sie weisen darüber hinaus auch die Möglichkeit auf, verschiedene Perspektiven einzubringen und durchzuspielen. Indem heterogene Elemente, etwa zeitgenössische wissenschaftliche Tatsachen, politische Statements, Elemente kulturhistorisch tradierter Narrationen (wie beispielsweise Anspielungen auf Mythologien), oder verschiedene Erzählperspektiven in eine narrative Struktur gebracht werden (die oft tradierte Formate zitiert), zeichnen sie einerseits gewisse Interpretationslinien vor. ${ }^{23}$ Durch ihre zukunftsprogrammatische Ausrichtung bleiben sie jedoch andererseits offen genug, um in der weiteren Rezeption neue Aktualisierungen des Dargestellten zu ermöglichen. Gerade dadurch erweisen sie sich im Verlauf der Geschichte als immer wieder anschlussfähig und aktualisierungsbedürftig. ${ }^{24}$

Haldanes und Mullers utopische Ausführungen basierten auf durchaus heterogenen Forschungsentwicklungen ihrer Zeit, etwa aus dem Feld der Embryologie, der Hormonforschung, der zellbiologischen In-vitro-Kulturtechniken, aber auch der Agrarwissenschaften und nicht zuletzt der sich neu formierenden Genetik. Deren technische Neuerungen wurden - und hier liegt der begründende Status dieser Utopien - in Richtung einer visionären Wissenschaft vom Leben gebündelt, die mit ihrer postulierten Möglichkeit, Vererbung und Reproduktion kontrollieren zu können, zum Schlüsselelement zukünftiger Gesellschaftsformen erhoben wurde. Tatsächlich erscheinen diese Utopien nicht nur aus dem historischen Abstand als konstitutives Element einer zu Beginn des Jahrhunderts neu heraufziehenden, auf die Kontrolle der Vererbung ausgerichteten biopolitisch motivierten Reproduktionsbiologie. ${ }^{25}$ Vielmehr lassen die Texte auch den Anspruch erkennen, dass sie als Gründungsnarrativ intendiert waren. In Mullers Out of the night, der Titel deutet es schon an, findet sich das grundlegende Aufklärungsnarrativ einer Kongruenz von naturwissenschaftlichem und gesellschaftlichem Fortschritt, zugespitzt auf die Potentiale einer zukünftigen Genetik.

Vor allem aber Haldanes Daedalus steht in der Tradition des utopischen Romans. Explizit wird die Nachfolge H.G. Wells angesprochen und die Erzählung als „Prophezeiung“ ausgewiesen (Haldane 1925: 8, 35). Der Figur des Daedalus wird in der Mythologie nicht nur die Nachahmung des Lebendigen in der Erschaffung von lebensecht aussehenden Skulpturen zugeschrieben, sondern ihm wird auch unterstellt, mit seinen Künsten behilflich gewesen zu sein, das erste menschlich-tierische Mischwesen hervorgebracht zu haben, den Minotaurus. Deshalb beschrieb Haldane ihn wohl auch als ersten Biologen. Mit dem Rückbezug auf die Figur des Daedalus 
wird die ganze Abhandlung in einen mythologischen Rahmen gestellt. Sie weist sich selbst, wie Susan Squier betont hat (1994: 69-73), als eine Art Gründungsmythos aus, der vor allem eine Botschaft enthält: dass im 20. Jahrhundert der kategoriale Wechsel von der Dominanz physikalischer und chemischer Erfindungen zu biowissenschaftlichen Interventionen zu sehen sein wird, und dass letztere in noch ungeahnter Weise selbst vermeintlich normative Kategorien wie die des „Natürlichen“ aufheben oder fundamental herausfordern werden. ${ }^{26}$

\section{Klonvisionen und ,transhumane' Phantasmen im biowissen- schaftlichen Diskurs der 1960er Jahre}

Nachdem in der unmittelbaren Nachkriegszeit genetische Züchtungsphantasien zumindest für eine Zeit diskreditiert gewesen zu sein schienen, erfuhr jene Spielart des eugenischen Diskurses der 1920er und 1930er Jahre, die durch sozialistische oder mit dem Sozialismus liebäugelnde Wissenschaftler in Absetzung von der damaligen rassenideologischen und nationalsozialistischen negativen Eugenik geprägt worden war, zu Beginn der 1960er Jahre neuen Auftrieb. Die zu dieser Zeit einsetzende Diskussion über die „neue Biologie" knüpfte bezüglich ihrer utopischen Grundlinien zunächst fast nahtlos an diesen älteren Diskurs an, was auch daran lag, dass insbesondere Muller, Haldane und Julian Huxley - also jene Wissenschaftler, die Daniel Kevles als Vertreter einer Reformeugenik bezeichnet hat (vgl. Kevles 1995: 173) - als maßgebliche Stimmen in der neu auflebenden Debatte wahrgenommen wurden. In zwei wesentlichen Aspekten jedoch verschob sich die Diskussion. Während im älteren eugenischen Diskurs vorrangig eine gesellschaftliche Dimension verhandelt wurde, rückte in den 1960er Jahren das Individuum in den Mittelpunkt. Daraus resultierte ein anders gelagertes utopisches Leitbild. Galten die eugenischen Bestrebungen zu Beginn des Jahrhunderts letztlich dem Ausgleich oder der Abwehr einer vermeintlich zur Degeneration neigenden kulturellen Evolution, so kehrte sich die Wahrnehmung von kulturell bedingten und biologischen Faktoren jetzt gewissermaßen um. Im Verlauf der 1960er Jahre entwickelten sich Phantasmen von der evolutionären Selbstüberwindung des Menschen, ermöglicht durch eine neue Dimension von Biotechniken. Motive, die dem älteren Eugenik-Diskurs entstammten, vermischten sich jetzt mit futuristischen Elementen der 1960er Jahre. Die Utopie des genetisch hochgezüchteten Menschen oder die Vorstellung, der Mensch könne seine eigene Evolution steuern, trafen jetzt auf einen durch Kybernetik und Weltraumszenarien vorbereiteten Raum, in dem die technische Überwindung des Körpers zum grundlegenden Topos gehörte. Kybernetische Phantasien des „halbmaschinisierten Supermenschen“ (Anonym 1966: 89) hatten bereits Mitte der 1960er Jahre die öffent- 
liche Diskussion erreicht. Dass die „Revolution der Evolution“ (ebd.) begonnen habe und dass die Menschheit auf dem besten Wege sei, „den uns heute bekannten Menschen (...) regelrecht abzuschaffen und durch andersartige Wesen“ zu ersetzen (Overhage 1967: 6), waren verbreitete futuristische Szenarien. $\mathrm{Zu}$ den Cyborg-Phantasien, welche primär die technische Überformung des Körpers symbolisierten, gesellte sich seit Mitte der 1960er Jahre die Vision des organismisch, gewissermaßen aus seinem Inneren heraus neu geformten und evolutiv weiterentwickelten Menschen der Zukunft - eine Vision, die in der Folgezeit mehr und mehr durch die Figur des menschlichen Klons repräsentiert wurde.

Der erste Hinweis darauf, dass die Forschungsarbeiten zum Zellkerntransfer, wie sie von Briggs und King in den 1950er Jahren in Philadelphia an Fröschen durchgeführt wurden, zukünftig womöglich in einem ganz anderen Kontext weiterentwickelt werden könnten, findet sich bereits sehr früh in einem Artikel von Muller. In einem Beitrag, der für die internationale Konferenz zur 100. Jahresfeier von Charles Darwins Origin of Species 1959 in Chicago verfasst und 1960 veröffentlicht wurde, diskutierte er diese Arbeiten als zukünftiges Mittel für eine eugenische Selektion von menschlichen Genotypen. Muller verwies hier auf die Techniken des embryonalen Zellkerntransfers von Briggs und King noch nicht unter der Bezeichnung des Klonens, sondern als eine „vielversprechende Art der Parthenogenese“ (1960: 453). Bevor diese an Fröschen entwickelte Technik jedoch „eugenische Bedeutung“ (ebd.) erlangen könne, müsse sie nicht nur an Säugetieren weiterentwickelt, sondern vor allem auf den Kerntransfer aus somatischen Zellen von Erwachsenen ausgedehnt werden. In Bezug auf die konkreten Bio-Techniken ging Mullers Zukunftsvision hier weit über das damals Faktische hinaus. Denn Briggs und King hatten gerade gezeigt, dass mit der Transplantation von Zellkernen aus vorangeschrittener Zelldifferenzierungsphase keine normale Embryonalentwicklung induziert werden konnte, und die in eine andere Richtung weisenden Ergebnisse der Gruppe von Fischberg und Gurdon aus Oxford waren Muller - dies wird aus seinem Text ersichtlich - zu der Zeit nicht bekannt. Der Genetiker Muller formulierte hier nicht nur eine andere Sicht vom Potential des Zellkerns als die Embryologen Briggs und King, vor allem sah er die anvisierten Möglichkeiten durchwegs als positive Bereicherung der Gesellschaft an. Mullers Klonszenario legte die Basis für die in der Folgezeit gängigen Vorstellungen von der Anwendung des Zellkerntransfers: nämlich die Erzeugung von vermeintlich identischen genetischen Kopien von auserwählten Individuen. Der Entwicklungsverlauf dieser als genetische Zwillinge betrachteten Klone sei bis zu einem gewissen Grade vorhersehbar, und ihre intellektuellen Kapazitäten seien steigerbar. In diesem Rationalisierungsaspekt sah Muller den großen Vorteil des Klonens für Individuum und Gesellschaft. Die Linien weiterer fiktiver Ausgestaltungen des Klonthemas formulierte er folgendermaßen aus: 
This type of parthenogenesis would make possible the production of multiple progeny that resemble their genetic parent and one another about as closely, phenotypically, as identical twins reared apart resemble one another and that are about as alike genetically as identical twins. Here, then, there would be an extremly high order of predictability regarding the nature of the children and virtually no regression except that occasioned by environmental factors, such as the manner of bringing up the children. Of course, the high general intelligence of the progenitor would in most cases be capable of being applied in very diverse directions in his separate manifestations, as we might term then. [...]

Thus far better opportunity could be provided to these outstanding persons for making the most of their unusaul potentialities. When one considers how much the world owes to single individuals of the order of capability of an Einstein, Pasteur, Descartes, Leonardo, or Lincoln, it becomes evident how vastly society would be enriched if they were to be manifolded. Moreover, those who repeatedly proved their worth would surely be called upon to reappear age after age until the population in general had caught up with them. (Muller 1960: 454)

Seit den 1920er Jahren hatte Muller die künstliche Befruchtung mittels Spermaspende herausragender Persönlichkeiten als eugenische Schlüsseltechnologie der Zukunft propagiert. Das Klonen über Zellkerntransfer war für ihn kein kategorial neuer Schritt, sondern nur eine qualitative Weiterentwicklung dieser anvisierten Praxis. Neben diesem eugenischen Argument für das Klonen finden sich bei Muller zwei weitere Begründungsstrategien. Zum einen verwies er darauf, dass im Reich der Organismen der Wechsel von geschlechtlicher und vegetativer Vermehrung durchaus erprobt sei und suchte damit die Technik des Zellkerntransfers zu naturalisieren. Zum zweiten brachte Muller das Argument der technischen Rationalisierung ins Spiel, indem er erneut klare Parallelen zog zwischen automatisierten technischen Produktionsverhältnissen im Allgemeinen (und ihren unausweichlich positiven sozialen und politischen Konsequenzen) und den biotechnischen Entwicklungen im Bereich der menschlichen Reproduktion (und ihren emanzipatorischen Folgen):

In this way, then, mankind would be able to reap the benefit of that alternation of asexual reproduction (for reliably multiplying types of tested worth) with techniques of sexual reproduction (for trying ever new combination), an alteration that has been so advantageous in some other classes of organisms. Later generations will look with amazement at the pitifully small amount of research now beeing carried on to open up such possibilities, even though for years specialists have realized that they lie just around the corner.

Just as our economic and political system is inevitably, although too slowly, being modified to fit our present technological capabilities of large-scale automatic production, despite the fervor with which men try to cling to their ancient preconceptions of how business and government should operate, so too on the biological side of human affairs the timehonored notions of how reproduction should be managed will gradually give way before the technological progress that is opening and will further open new and more promising possibilities. (Ebd.: 454f.)

Muller diskutierte in diesem Text nicht nur das Klonen, sondern auch direkte Eingriffe in die genetische Natur des Menschen als eine zweite Technik zur Verbesserung der genetischen Disposition, etwa durch Veränderungen von Nukleotidsequenzen einzelner Gene. ${ }^{27}$ Bereits Ende der 1950er Jahre 
lagen Spekulationen über diese Form des genetic engineerings in der Luft, was wiederum dem damals faktisch Gesicherten weit vorauseilte. Zu dieser Zeit stand der genetische Code zwar im Brennpunkt molekularbiologischer Diskussionen, die experimentelle Erforschung des sogenannten Coding-Problems steckte jedoch noch in den Anfängen. Interessanterweise zeigte Muller, der als Genetiker oft dem reduktionistischen Lager zugerechnet wird, sich hier überaus skeptisch über die Möglichkeiten direkter Eingriffe, da das Wissen über die Wirkungsweise der Gene in der „inordinately complex economy of the human organism" (ebd.: 454) noch gänzlich fehle. Für den Genetiker war dieses Defizit ein weiteres Argument für die Weiterentwicklung embryologischer Methoden (wie dem Zellkerntransfer), die anstelle der genetischen Veränderung auf die Selektion ganzer Genotypen zielten, da diese Techniken im Gegensatz zu ersteren "just around the corner" lägen (ebd.: 454).

Der Kontext, in dem Mullers Ausführungen standen, ist nicht unerheblich für die Einschätzung ihrer Tragweite. Die Gedenkfeier für Darwin, von dem Anthropologen Sol Tax in mehrjähriger Vorbereitungsphase in Chicago organisiert, war nicht nur in der US-amerikanischen Wissenschaftslandschaft das bedeutsamste Großereignis im Darwin-Jahr 1959. Die Konferenz, über deren Verlauf in Zeitungen, Radio- und TV-Sendungen berichtet wurde, brachte rund fünfzig prominente Vertreter verschiedenster Felder, insbesondere der Evolutionstheorie, Populationsgenetik und Anthropologie, zusammen, die eine Gesamtschau evolutionstheoretischer Ansätze in Biologie, Kultur und Gesellschaft darlegen sollten. Als Ehrengast, der die in der Öffentlichkeit wegen ihres antireligiösen Inhalts höchst kontrovers diskutierte zentrale Gedächtnisrede hielt, wurde Julian Huxley begrüßt, ein Enkel des Darwin Verfechters Thomas Huxley und prominenter Mitbegründer der „evolutionären Synthese“.28

Julian Huxley, wie Muller ein Befürworter eugenischer Maßnahmen, vertrat eine evolutionstheoretisch fundierte Weltauffassung, die den Gedanken des evolutionären Fortschritts ins Zentrum setzte. Diese Betonung sowie der daraus abgeleitete „evolutionäre Humanismus“ waren zwar unter Evolutionstheoretikern der Zeit durchaus umstritten ${ }^{29}$, sie fanden jedoch durch Huxleys überaus großes populärwissenschaftliches Engagement eine weite Verbreitung. Während Mullers eugenische Auffassung materialistisch fundiert war, propagierte Huxley eine allumfassende, die Gegensätze von Religion, Wissenschaft und Kunst überwindende (fast schon als idealistisch zu bezeichnende) Weltanschauung. Muller verortete die Triebkraft für Veränderungen sozialer und politischer Systeme in den technologischen Entwicklungen, Huxley dagegen sah einen neuen evolutionären Zustand erreicht, in dem das menschliche (Selbst-)Bewusstsein in die Lage versetzt war, die weitere evolutionäre Zukunft aktiv zu gestalten. In seiner „neuen und revolutionären Schau der Wirklichkeit“, die „wie jede echte Schau [...] pro- 
phetisch“ sei (J. Huxley 1965 [1964]: 115), propagierte er den Menschen als alleinige Triebkraft weiterer evolutionärer Entwicklungen, sowohl der äußeren Natur als auch der inneren. Damit war für ihn die „Eugenik - d.h. die genetische Verbesserung des Menschen - unweigerlich eines der Hauptziele des evoluierenden Menschen" (ebd.: 279). So unterschiedlich Mullers and Huxleys Ansätze in ihren Grundannahmen waren, so findet sich in beiden die Vorstellung, dass der kulturelle und soziale Fortschritt untrennbar mit dem genetischen verbunden ist. Die Selbstbewusstwerdung der Evolution im Menschen, die damit verbundene Aufforderung zum schöpferischen Selbstentwurf und zum evolutionär-eugenischen „Fortschritt“ waren Elemente einer Denkfigur, die in die Nähe dessen kommt, was Katherine Hayles in ihrer Analyse der Kybernetik und der Forschung zur Künstlichen Intelligenz als „Posthumanismus“ bezeichnet hat, als die Vision der schöpferischen Selbstüberwindung vermeintlich entkörperter Subjekte (vgl. Hayles 1999). In der Tat sprach Huxley selbst bereits 1957 vom „Transhumanismus“ für die von ihm konstatierte neue evolutionäre Phase menschlicher Existenzweisen: „The human species can, if it wishes, transcend itself [...] in its entirety, as humanity. We need a name for this new belief. Perhaps transhumanism will serve." (J. Huxley 1957: 17, Herv. i. Original)

Der kurze Exkurs zu Julian Huxley verdeutlicht den zeitgenössischen diskursiven Hintergrund, vor dem die Figur des Klons in biopolitischen Utopien der 1960er Jahre Gestalt annahm. Insbesondere Joshua Lederberg, der 1958 im Alter von nur 33 Jahren den Nobelpreis für seine Arbeiten im Feld der Bakteriengenetik bekommen hatte, entwickelte die Utopien des Transhumanismus oder der evolutiven Selbstüberwindung des Menschen weiter, auch wenn er die Begriffe selbst nicht benutzte. Indem er diese Phantasmen mit konkreten Entwicklungen in der Molekularbiologie und Zellbiologie verknüpfte, gab er ihnen neue Evidenz. Bereits 1962, auf dem von der Ciba Foundation finanzierten Symposium zum Thema „Man and His Future“, diskutierte Lederberg die „biologische Zukunft des Menschen“ vor dem Hintergrund der neuesten molekularbiologischen Entwicklungen (Lederberg 1966a).

\section{Das Ciba-Symposium und die Verknüpfung von Molekular- biologie mit futuristischen eugenischen Szenarien}

Der Einfluss, den das Ciba-Symposium auf die öffentliche Wahrnehmung der modernen Lebenswissenschaften und ihrer gesellschaftlichen Auswirkungen hatte, kann wohl kaum überschätzt werden. ${ }^{30}$ Führende Biowissenschaftler, darunter nicht wenige Nobelpreisträger, diskutierten, was sie als dringende Zukunftsprobleme der Menschheit ansahen. Ein beachtlicher Teil dieser Diskussion galt einer drohenden globalen Überbevölkerung und 
deren Konsequenzen sowie den Möglichkeiten eugenischer Interventionen. In diesem Kontext skizzierte auch Haldane ein Zukunftsszenario der Menschheit, in dem das Klonen als vegetative Vermehrung eine wichtige Rolle spielte. Mit explizitem Bezug auf Brave New World sprach Haldane von der "klonischen Vermehrung" als einer möglichen Reproduktionsform der Zukunft, wobei er den Diskussionslinien folgte, die Muller bereits vorgegeben hatte, nämlich die Reproduktion von Menschen mit außergewöhnlichen Begabungen (Haldane 1966: 382f.). Muller selbst diskutierte auf dem Symposium einen ganzen Katalog von Zukunftstechniken selektiver, eugenischer Maßnahmen. Allen voran plädierte er für die Einrichtung von Samenbanken ausgewählter Spender, und er prognostizierte die Möglichkeit der "Manipulation des genetischen Materials“ durch die Anwendung zukünftiger „Nano-Nadeln“ oder die „klonische Fortpflanzung, etwa durch Übertragung unreduzierter Nuclei auf Eier“" (Muller 1966: 290). Lederberg stellte auf dem Symposium der tradierten Form der Eugenik, deren Selektionsdenken ein evolutionstheoretisches und daher zeitlich langfristiges Modell zugrunde liege, die von ihm so bezeichnete, wesentlich kurzfristiger wirksame „Euphänik“ als Steuerung der menschlichen Individualentwicklung zur Seite (Lederberg 1966a: 293). Vor allem in der Molekulargenetik (und ihren zukünftigen Möglichkeiten, die genetische Informationsübertragung zu steuern) und in der Zellbiologie sah er die beiden Hauptfelder für nicht allzu fern liegende Möglichkeiten, in die Natur des Menschen plastisch einzugreifen. Schon bald, in nur ein bis zwei Generationen, seien Manipulationen der Chromosomendiploidität, "gametische Selektion“ und der Austausch von Chromosomensegmenten genauso möglich wie die Regulation der menschlichen Gehirngröße durch vorgeburtliche und frühe nachgeburtliche Eingriffe (ebd.: 294f.).

Richtungsweisend für die Verknüpfung von Phantasmen des „Transhumanen" mit molekular- und zellbiologischer Technikentwicklung ist ein Artikel Lederbergs zu „Experimental Genetics and Human Evolution“, den er 1966 in leicht abgewandelten Fassungen an zwei prominenten Orten veröffentlichte: in der 100. Jubiläumsausgabe von The American Naturalist, dem offiziellen Publikationsorgan der American Society of Naturalists (Lederberg 1966c), und im Bulletin of the Atomic Scientists (Lederberg 1966b), einer Zeitschrift, die sich dezidiert dem Verhältnis von Wissenschaft und Gesellschaft widmete. Hier entwickelte Lederberg eine spezifische Vision des „genetic design“ (ebd.: 9), für deren Forschungsprogrammatik er den Begriff der "Algeny" einführte. Darunter verstand er eine Art „genetische Alchemie“, eine gentechnische Transformation des Humanen. Zwischen den Rollen des Mahners und des engagierten Befürworters wechselnd, argumentierte Lederberg - ähnlich, wie es bereits in den Utopien von Muller oder Haldane ersichtlich war - primär mit der Unausweichlichkeit einer durch Biotechniken geprägten und vor allem vorangetriebenen Zukunft: 
Recent discussions of controlled human evolution have focussed on two techniques: selective breeding or eugenics, and genetic alchemy, or algeny. Their implementation will doubtless proceed even without an adequat basis of understanding of human values, not to mention vast gaps in human genetics. (Ebd.: 11)

In der Hochphase der Weltraumeuphorie - „in one life-time“, so Lederberg begeistert, „the parish has become the solar system“ (1966c: 520) - erörterte er, dass man in der Zukunft womöglich Klonpaare erschaffen könne, die aufgrund der Identität ihres Nervensystems über eine außergewöhnliche Kommunikationsgabe untereinander verfügten und damit für besondere Arbeitseinsätze im Weltall oder auch in der Tiefsee gebraucht werden könnten. Die Erzeugung von menschlich-animalischen Zell-Hybriden mittels Transplantation menschlicher Zellkerne zu Forschungszwecken im Labor war eine weitere Möglichkeit, die er erwähnte (Lederberg 1966b: 11). Ebenso brachte er bereits damals den medizinischen Vorteil ins Spiel, den das Klonen zukünftig für Organtransplantationen haben könnte (ebd.: 10f.).

Das Klonen und die genetische Transformation des Menschen auf der Ebene der DNA waren für Lederberg die zwei zentralen technischen Direktiven der evolutiven Selbstgestaltung des Humanen:

I infer, that the path to algeny already opens up two major diversions of human evolution: clonal reproduction, and introduction of genetic material from other spheres. Indeed the essential features of these techniques have already been demonstrated in vertebrates, namely, nuclear transplantation in amphibia, and somatic hybridization of a variety of cells in culture, including human. (Ebd.: 11)

Die Möglichkeit, in die biologische Natur des Menschen einzugreifen, diskutierte Lederberg als Akt der individuellen Selbstbefreiung, womit zugleich eine Neudefinition menschlicher Individualität notwendig wurde. Als Schlüssel dazu betrachtete er das Potential zur Kommunikation, womit er einerseits zukünftig neu in Erscheinung tretende humanoide und intelligenzfähige Geschöpfe wie Roboter in die Kategorie des Humanen einschloss ${ }^{31}$, und andererseits schon einmal die resultierenden Kreaturen fehlgeschlagener biotechnischer Transformationen des Menschen, jene von ihm als „subhuman" oder "parahuman" bezeichneten Wesen, prophylaktisch ausgrenzte. ${ }^{32}$

Es verwundert nicht, dass diese technikphantastischen, futuristischen und eugenischen Szenarien schnell ihr Echo im populären Raum fanden. In dem futurologischen Bestseller Der Zukunftsschock zitierte Alvin Toffler 1970 aus einem Interview mit Lederberg, in dem dieser betont hatte, das Klonen werde „jedenfalls innerhalb der nächsten fünfzehn Jahre geschehen“.33 Bereits zwei Jahre zuvor hatte der britische Wissenschaftsjournalist Gordon Rattray Taylor in Die biologische Zeitbombe, ein Buch, das monatelang auch in westdeutschen Bestsellerlisten zu finden war, dem Klonen ein ganzes Kapitel gewidmet und Mullers, Haldanes und Lederbergs Szenarien weiter ausgestaltet (Taylor 1969 [1968]: 30-33). Aber nicht nur im Genre der populären Wissenschaftsdarstel- 
lungen wurde das Klonen Ende der 1960er Jahre zu einem zentralen Thema. Die durchaus ernst genommenen Technik- und Weltraumphantasien taugten auch als Fallbeispiel ethischer Positionen. 1972 erörterte beispielsweise der Theologe und Bioethiker Joseph Fletcher als Reaktion auf Leon Kass, der in den USA die ersten ethischen Stellungnahmen gegen das Klonen formuliert hatte (vgl. Kass 1972), dass zukünftig Situationen eintreten könnten, in denen das Klonen oder die positive Eugenik gerechtfertigt seien. In diesem Kontext diskutierte Fletcher das von Lederberg ins Spiel gebrachte Szenario der im Weltraum einsetzbaren Klongruppe mit utilitaristischer Akzentuierung:

\footnotetext{
There may be a need one day, in the human situation at large, for one or more people especially constituted genetically to survive long periods outside a bathysphere at great marine depths or outside space capsules at great heights. If the greatest good for the greatest number were served, it would be justifiable not only to specialize people by cloning or constructive genetic engineering but also to bio-engineer or bio-design para-humans or >modified men as chimeras (part animal) or cyborg androids (part prostheses). (Fletcher 1972: 83)
}

Über die „subhumanen“ Kreaturen fehlgeschlagener biowissenschaftlicher Forschung hinaus wurde hier ein weiteres Zukunftsbild posthumaner Geschöpfe entworfen, in dem Szenarien, die seit Huxleys Brave New World bekannt waren, wieder auflebten. Im Kontrast zur Vision von der Reproduktion außergewöhnlicher intellektueller Begabungen wurde hier das Bild der Klone als parahumane Arbeitsmaschinen skizziert.

\section{Transhumanismus und Subjektivität. Literarische Anthropologie des „Klons”}

Innerhalb weniger Jahre hatte sich die Figur des Klons in den Debatten soweit etabliert, dass Lederberg bereits 1970 von einer „'clone-a-man' metaphor“ (Lederberg 1970: 1310) sprechen konnte: „It does serve as a metaphor to indicate that future generations will have infinitely more powerful ways than we do to deal with whatever they may regard as socially urgent issues of human nature." (Ebd.: 1309) In der Tat kann der Klon zu dieser Zeit in mehrerlei Hinsicht als eine Metapher betrachtet werden. Er wurde, wie das Zitat von Lederberg verdeutlicht, zum Symbol zukünftiger biopolitischer Interventionen, wobei die Figur viel Projektionsfläche zur weiteren imaginativen Ausgestaltung ließ. Damit ging eine Vervielfältigung der Kontexte einher, in dem der Begriff des Klons Verwendung fand. In nur einem Jahrzehnt hatte der ehemals esoterische Begriff, der nur in spezifischen biowissenschaftlichen Forschungskontexten in einem technischen Sinn verwendet worden war, den öffentlichen Raum erobert.

Gegen die szientistische Deutungsmacht der menschlichen Natur und die drohende Auflösung der Kategorie des Humanen regte sich in den 
1970er Jahren mit der beginnenden ethischen Debatte zur modernen Biomedizin, Genforschung und deren „Ingenieurspotential“ (Jonas 1987 [1974]: 162) nicht nur von philosophischer Seite, sondern auch von literarischer Seite aus Widerstand. So sprach beispielsweise Hans Jonas 1974 vom „metaphysischen Schauder“, der ihn bei dem "Gedanken an den Greuel menschtierischer Zwitterbildungen“ überkomme, und führte als Hauptargument gegen die biowissenschaftlichen Klonphantasien das Recht auf Nichtwissen der eigenen genetischen Zukunft ein (ebd.: 200f.). Während jedoch der philosophische Klon-Diskurs zu dieser Zeit erst zögerlich begann, stellte die zunehmende literarische Verarbeitung des Themas seit Ende der 1960er Jahre einen fiktiven Raum durchaus auch für die ethische Auseinandersetzung mit den Biowissenschaften bereit.

Was zeichnete nun diese literarischen Fiktionen im Vergleich zu den Wissenschaftsfiktionen aus? Zunächst gilt es festzuhalten, dass sich die literarischen Klonfiktionen auf die biopolitischen Utopien der 1960er Jahre bezogen und nicht auf die konkreten experimentellen Forschungsarbeiten zum Klonen. Die Texte verdeutlichen, dass sich die Autorinnen und Autoren nicht mit den konkreten Experimentalpraktiken beschäftigt hatten. Auch die rein fiktive, aber überaus detailreiche Ausgestaltung technischer Szenarien, sonst ein Charakteristikum des Genres, spielte in der Science Fiction über Klone in dieser Zeit kaum eine Rolle. Nicht das fiktive Spiel mit biotechnologischen Entwicklungen als solchen war das Anliegen, sondern die Auseinandersetzung mit der sich im biowissenschaftlichen Diskurs abzeichnenden Frage, was Menschsein unter diesen technischen Bedingungen bedeuten kann. Die literarische Ausgestaltung des Klonthemas war eine unmittelbare Reaktion auf die durch einige Biowissenschaftler popularisierten szientistischen KlonUtopien. Die Science Fiction erfüllte, was in Anlehnung an den Literaturwissenschaftler Nicolas Pethes als „literarische Anthropologie der Lebenswissenschaften" (vgl. Pethes 2005) bezeichnet werden kann. Sie war weder primär wissenschaftliche Utopie noch ethische Dystopie, sondern ging mit ihren fiktiven zukünftigen Klon-Szenarien der sich wandelnden kategorialen Bestimmung des Menschen zwischen Gesellschaft und Biotechnik nach und erprobte damit kulturelle und anthropologische Anschlussfähigkeiten der biotechnischen Entwicklungen.

Obwohl auch die literarischen Erzählungen zumeist an bereits existierende populäre Klon-Visionen anknüpften, waren sie in der Lage, Umdeutungen vorzunehmen und damit auch neue Deutungsangebote zu liefern. Dem drohenden Verlust des Humanen angesichts der biotechnischen Entwicklungen traten sie, und dies ist ihr entscheidender Beitrag für eine semantische Neubesetzung der Thematik, mit einer Re-Humanisierung des Klons entgegen. Damit lösten sie die Figur aus den bio-utopischen, eugenisch motivierten Visionen der 1960er Jahre heraus und stellten den technischen Visionen von der Überwindung des Menschen die Frage nach der Psychologie und Subjek- 
tivität des Klons entgegen. Nur zwei Beispiele seien an dieser Stelle ausführlicher angeführt: die Kurzerzählung Nine Lives von Ursula K. Le Guin und der Roman Cloned Lives von Pamela Sargent. ${ }^{34}$

Zuerst 1969 im Magazin Playboy veröffentlicht, gehört Nine Lives zu den frühen literarischen Werken, in denen die Figur des menschlichen Klons verarbeitet wird. Der Klon erscheint hier weder als ,Übermensch' noch als monströse Bedrohung. Le Guin ließ sich durch bereits zirkulierende KlonVisionen inspirieren. So erklärte sie später, sie sei durch Taylors Sachbuch Die biologische Zeitbombe auf den Stoff aufmerksam geworden, habe das Thema „jedoch qualitativ, psychologisch entwickelt“ (Le Guin 1980: 161). Le Guin greift in ihrer Erzählung das von Lederberg entworfene Bild der Klongruppe auf, die über eine telepathische Kommunikationsgabe verfügt. Im Mittelpunkt der Geschichte steht ein sogenannter Zehner-Klon, eine Gruppe von Frauen und Männern, die alle vom Ingenieur John Chow geklont wurden. Das Arbeitsteam wird zu einem extra-terrestrischen Einsatz auf einen anderen Planeten geschickt, um dort stationierte Wissenschaftler bei geologischen Arbeiten zu unterstützen. Zu Beginn erscheint die Klongruppe als geschlossenes Kollektiv, das keiner Interaktion mit anderen bedarf. Es kommt jedoch zu einem unterirdischen Grubenunfall, den nur ein einziges Geschöpf aus der Gruppe überlebt. Dieser einzelne Klon ist nun gezwungen, sich erstmals als eigenständiges Individuum zu begreifen. Erzählt wird eine Geschichte der Individualisierung, gewissermaßen der Menschwerdung des Klons: darüber, dass der Klon in der Interaktion mit anderen grundlegende menschliche Erfahrungen wie Einsamkeit und Fremdheit, aber auch Mitleid und Freundschaft durchlebt. Mit dieser psychologischen Akzentuierung der Klon-Figur präsentiert Le Guin ein Motiv, das in verschiedenen Erzählungen über Klone in den 1970er Jahren weitere Ausgestaltung erfuhr.

Indem sie die Frage nach der Subjektivität und Individualität der Klonfigur durchspielte, orientierte sich die literarische Fiktion an Strukturen, die dem Muster von Bildungsnarrationen folgten. Daraus resultierte jedoch auch eine neue Perspektive. In der Romanliteratur wurde damit die ethisch brisante Frage entdeckt, was es für ein zukünftiges Geschöpf bedeuten würde, mit dem Wissen zu leben, die genetische Kopie eines anderen zu sein. Besonders deutlich findet sich diese ethische Ausrichtung in dem 1976 veröffentlichten Roman Cloned Lives, in dem das Klonexperiment und sein ungewisser Ausgang aus einer durchgängig psychologischen Perspektive verhandelt wird. Der Roman, dessen Handlung im Jahre 2000 beginnt, erzählt davon, wie sich der Physiker Paul Swenson aus teils wissenschaftlichem, teils narzisstischem Interesse klonen lässt. Als Motivation für das Experiment wird angeführt, was als ,Muller-Haldane-Szenario' beschreibbar ist, nämlich der Wunsch, die mannigfaltigen intellektuellen Anlagen des schon etwas älteren Paul Swenson zu vervielfältigen und in Form seiner geklonten Nachkommen für die 
Gesellschaft nutzbar zu machen. Auch andere Elemente der Debatte über das Klonen werden zu Beginn der Erzählung aufgegriffen, etwa wenn die Figur eines Geistlichen im Gespräch mit dem durchführenden Genetiker und Paul Swenson mahnt:

Im Augenblick werden sie nicht als Kinder angesehen, sondern als etwas Furchterregendes. Manche Zeitungsberichte sprechen von Massenhirnen oder Telepathie zwischen Klonen. Irgendwo stand sogar, sie könnten dazu verurteilt sein, zur selben Zeit alle dasselbe zu tun. Vielleicht sehen die Menschen sie mit anderen Augen, wenn sie geboren sind. (Sargent 1980 [1976]: 46)

Geschildert wird der Lebensweg seiner Klongruppe als eine Art familiäre Bildungsgeschichte über vierzig Jahre hinweg. Jedem der fünf SwensonKlone ist ein Kapitel gewidmet, in dem die Geschehnisse aus der personalen Erzählperspektive der jeweiligen Figur geschildert werden. Die Leser und Leserinnen erhalten so Einblick in die spezifische Gefühlslage der Klone und nehmen die erzählte Welt aus ihrer Sicht wahr. Nicht nur durch diese Erzählweise wird die ethische Frage nach der Identität und Differenz der Klonfiguren parabelhaft durchgespielt, sondern die Autorin positioniert die Erzählung auch explizit in den Kontext der beginnenden bioethischen Debatten. Mit eingestreuten und jedem Kapitel vorangestellten Zitaten wird im Roman auf einer weiteren Ebene der thematische Rahmen der damaligen Diskussion skizziert und das diskutierte Gefahrenpotential des Klonens vorgeführt: Durch genetische Manipulation und Modifizierung des Menschen könnten zukünftig verschiedene Typen oder gar verschiedene Arten entstehen, die sich weitgehend vom heutigen Menschen unterscheiden; Klone könnten unsere Auffassungen von der Einzigartigkeit des Individuums untergraben und gängige Vorstellungen von Familienstrukturen außer Kraft setzen. Nicht zuletzt zitiert Sargent das seinerzeit immer wieder beschworene Angstszenario, wonach im geklonten Menschen vor allem ein gleichgeschaltetes Kollektivwesen gesehen wird. Dem wird in Cloned Lives jedoch konsequent eine Figuration des Klons entgegengehalten, die auf eine Ebene des allgemein Menschlichen referiert und die Individualität des einzelnen Klon-Geschöpfes hervorhebt. Ähnlich wie in Le Guins Erzählung erscheint die Kategorie der individuellen Erfahrung als das wesentliche Moment einer auch den Klonen möglichen Identitätsbildung. Die dargestellten Probleme der Swenson-Klone unterscheiden sich dabei nicht prinzipiell von denen anderer Jugendlicher auf dem Wege in die Welt der Erwachsenen. Als am Ende der Erzählung eine der Klonfiguren gefragt wird: „Wie war das, Mr. Swenson? Einer der ersten gewesen zu sein, meine ich", liest sich die Antwort wie eine Art Resümee der erzählten Klongeschichten:

Jim schwieg eine Weile. ,In mancher Beziehung war es schwer, antwortete er schließlich. ,Wir waren anders, und die Leute hatten ein bisschen Angst. Aber die meiste Zeit hatten wir dieselben Probleme wie alle anderen Menschen auch‘. (Ebd.: 222) 


\section{Die zwei und mehr „Kulturen” des Klons}

Was lässt sich aus der Analyse der wissenschaftlichen und literarischen Klonfiktionen der 1960er und 1970er Jahre in Bezug auf die Zwei-KulturenDebatte festhalten? Das Anliegen in diesem Beitrag war, die Diskussion über Snows These von den „zwei Kulturen“ historisch als Element einer größeren Debatte über die Frage nach wissenschaftlichem und gesellschaftlichem Fortschritt und den Bedingungen der menschlichen Existenz in einer durch Technik und Wissenschaft grundlegend geprägten Welt darzustellen. Die in Folge von Snow einsetzende Debatte steht gewissermaßen symptomatisch für einen spezifischen Nachkriegsdiskurs und verdeutlicht die weitreichenden Verunsicherungen bezüglich der Bewertung und der Folgen naturwissenschaftlicher und technischer Entwicklungen. Vor diesem Hintergrund wurde die Entstehung der Figur des Klons exemplarisch als Feld der Auseinandersetzung mit einem neu heraufziehenden, gesellschaftlich folgenreichen Faktor der Naturwissenschaften untersucht: einer sich in den 1960er Jahren abzeichnenden neuen Biologie, die durch die molekularbiologischen Praktiken und Erkenntnisse absehbar die Frage nach der „Natur“ des Menschen herausforderte.

Entgegen der immer wieder postulierten Kluft zwischen zwei Wissenskulturen, in der vor allem auf eine Trennung auf der Ebene von Wissenschaftsordnungen, ihrer disziplinären Ausdifferenzierung und Spezialisierung sowie damit verbundener Selbstverständnisse rekurriert wird, wurden hier verschiedene Kulturen im biowissenschaftlichen Feld selbst differenziert. So zeigt sich, dass die Klonforschungen an Fröschen zwar biopolitischen Utopien von der Kontrolle der Vererbung und der technischen Selbstüberwindung des Menschen Vorschub leisteten, jedoch in einem anderen Feld, in einer anderen Experimentalkultur als der der Reproduktionsforschung angesiedelt waren. Umgekehrt wurde gezeigt, dass es im biowissenschaftlichen Diskurs eine mindestens seit den 1920er Jahren anhaltende Tradition der Formulierung von visionären und utopischen Programmatiken seitens prominenter Biowissenschaftler gab, die eine deutliche Nähe zum utopischen Roman beziehungsweise zur Science Fiction (die im engeren Sinne ebenfalls ein Produkt der 1920er Jahre ist) aufwiesen. Im Rahmen dieser, für das biowissenschaftliche Selbstverständnis durchaus zentralen, utopischen Kultur, die hier Wissenschaftsfiktion genannt wurde, wurden in den 1960er Jahren die ersten Zukunftsvisionen vom geklonten Menschen formuliert und, grundlegender, die Frage nach dem Humanen in einer biotechnologischen Welt neu ausgerichtet. Die Phantasmen vom geklonten Menschen der $\mathrm{Zu}$ kunft wurden zunächst von einer Gruppe prominenter Biowissenschaftler vorangetrieben, sie wurden jedoch schnell im populären Sachbuch, in der philosophischen Diskussion und vor allem in der literarischen Fiktion aufgegriffen. Die Figur des Klons wurde ein Element technologisch inspi- 
rierter futuristischer Visionen, in denen die biopolitische Kontrolle über die menschliche Reproduktion zentral war, sie wurde als Symbol der menschlichen „Entsubjektivierung“ durch die Technik diskutiert und nicht zuletzt in der Science Fiction aufgrund ihrer psychologischen Brisanz aufgegriffen. Während in den philosophischen Reflexionen der 1970er Jahre den Visionen vom genmanipulierten und geklonten Menschen entweder normativ begegnet wurde oder sie als letzte Konsequenz einer ökonomisch-technischen Verwertungsrationalität gedeutet wurden (vgl. Anders 2002 [1980]: 24f.), lieferte die fiktive Ausgestaltung des Themas in der Literatur eine andere Antwort auf die anthropologischen Verunsicherungen. Indem in einigen der Erzählungen und Romane die Subjektivität und Individualität der Klonfigur in den Blick genommen wurden, trug die Science Fiction dazu bei, die auf die Transformation des Humanen zielenden biotechnischen Utopien der 1960er Jahre wieder in den Raum des Menschlichen einzubinden. Letztlich lieferte sie damit eine vielschichtige, aber auch affirmative Antwort auf die technisch inspirierten Visionen, in der so grundsätzliche Kategorien wie Identität, Subjektivität und Humanität jedoch nicht infrage gestellt wurden.

Open Access This article is distributed under the terms of the Creative Commons Attribution Noncommercial License which permits any noncommercial use, distribution, and reproduction in any medium, provided the original author(s) and source are credited.

\section{Anmerkungen}

1 Die im folgenden Beitrag präsentierten Ergebnisse gehen auf eine Projektidee zurück, die am Zentrum für Literatur- und Kulturforschung in Berlin im Rahmen einer Forschungskooperation zur Trennungsgeschichte von Natur- und Geisteswissenschaften erste Formen angenommen hatte und im Rahmen eines von der DFG geförderten Projekts zur Geschichte der Klonforschung in Deutschland weiter ausgearbeitet wurde. Für anregende Diskussionen danke ich Caroline Welsh, Mai Wegener, Bernhard Dotzler und Karlheinz Barck.

2 Snow (1905-1980) hatte in den 1920er Jahren Chemie und Physik am Leicester University College studiert und war anschließend am Cavendish Laboratory in Cambridge tätig. Während des Krieges arbeitete er im Civil Service, wo er für die Rekrutierung von Physikern für den Kriegseinsatz zuständig war. Bereits 1932 hatte er seinen ersten Roman Death Under Sail veröffentlicht, nach dem Krieg war er für die English Electric Company tätig. 1964 bis 1966 arbeitete er für die Labour Regierung im neu eingerichteten Ministerium für Technologie (vgl. Collini 1993: xvii-xxii).

3 Gleichermaßen befürwortet wie attackiert, fand Snows Vortrag schon unmittelbar nach der Veröffentlichung ein „frappierendes, weltweites Echo von New York bis Moskau, von Tokio bis Warschau und Budapest", wie der Herausgeber der deutschen Ausgabe 1968 rückblickend betonte (Kreuzer 1987 [1968]: 7). Snows Rede wurde 1959 zunächst in der Zeitschrift Encounter abgedruckt. Im gleichen Jahr erschien sie noch als Buchfassung (die im selben Jahr drei Auflagen erlebte), bis 1962 erreichte diese bereits die 10. Auflage. Während die ersten Reaktionen auf Snow eher zustimmend waren, geriet seine Zwei-Kulturen-These erst nach dem kritischen Beitrag des britischen Literaturwissenschaftlers Frank Leavis (im Spectator 1962) zur sogenannten Snow-Leavis-Kontroverse. Zur Rezeption von Snow vgl. Collini 1993: xxix-xlii. 
4. 1961 gelang es zwei Wissenschaftlern an den National Institutes of Health, Marshall Nirenberg und Heinrich Matthaei, die erste Zuordnung zwischen einem Basentriplett der Nukleinsäure und einer Aminsosäure auf biochemischem Wege aufzuklären. Dies löste in einer Reihe von westeuropäischen und US-amerikanischen Laboratorien einen Forschungswettlauf um die weitere ,Entzifferung' des ,genetischen Codes' aus (vgl. Kay 2000).

5 Vgl. Snow 1987b [1963]: 74. Snow nannte explizit die Röntgenkristallographie, die ihm selbst sicherlich aus seiner Zeit am Cavendish Laboratorium in Cambridge vertraut war, und sah hier Anknüpfungspunkte für Künstler.

6 Snow selbst sprach von einer "geistigen Revolution“ (Snow 1987b [1963]: 76). Nicht zu vergessen ist, dass bereits sein Vortrag von 1959 den Titel: „Die zwei Kulturen und die wissenschaftliche Revolution“ trug. Eines seiner Hauptargumente war, dass die literarische Elite die Bedeutung der naturwissenschaftlichen und der damit verbundenen gesellschaftlichen „Revolutionen“ nicht wahrnehme bzw. eine Auseinandersetzung damit verweigere. Während er in seinem Vortrag noch vor allem auf Revolutionen in der Physik seit dem späten 19. Jahrhundert (Atomforschung und Thermodynamik) Bezug genommen hatte, sprach er 1963 als neues revolutionäres Feld die Biowissenschaften (Molekularbiologie und Neurophysiologie) an.

7 Vgl. dazu beispielsweise Cordle 1999, Cartwright/Baker 2005.

8 Huxley forderte Schriftsteller dazu auf, stärker naturwissenschaftliche Themen aufzugreifen. Im ethischen Korrektiv sah Huxley „eine der obersten Pflichten der Dichter und Schriftsteller“ im 20. Jahrhundert (A. Huxley 1963: 101). Darüber hinaus jedoch zielte er auf die Differenzen zwischen Literatur und Wissenschaft, indem er tradierten Unterscheidungen folgte: Subjektivität versus Objektivität, Singularität versus Verallgemeinerung, sprachlicher Ausdruck des Unaussprechlichen im Raum des Poetischen versus sprachökonomische und auf Eindeutigkeit festgelegte Ausdrucksweise in den Naturwissenschaften.

9 Ein Hauptkritikpunkt Snows zielte darauf, dass die Literaten kein soziales Engagement aufwiesen. Er ging zwar nicht ganz so weit zu behaupten, dass „die Auswirkungen all dessen, was sie [d. i.: die meisten berühmten Schriftsteller des 20. Jahrhunderts, C.B.] vertraten, Auschwitz mit möglich gemacht" hätten. Diese Einschätzungen wies er jedoch auch nicht ganz zurück und sah einen Zusammenhang zwischen „gewissen Strömungen der Kunst des frühen 20. Jahrhunderts und den absurdesten Äußerungen unsozialen Empfindens“ (Snow 1987a [1959]: 24).

10 "Gedichte“, so Habermas, „entstehen durch den Anblick von Hiroshima und nicht durch die Verarbeitung von Hypothesen“ (1987 [1966]: 315).

11 Vgl. dazu Dotzler, der von einer „antisophistischen Urszene“ spricht (2002: 107).

12 Bis zur Mitte des 20. Jahrhunderts war der Begriff „Klon“ ein zumeist nur in biowissenschaftlichen Fachartikeln erscheinender, technischer Terminus zur Bezeichnung von Pflanzen oder Zellen, die einen gemeinsamen, identischen Ursprung hatten. Die Bezeichnung referierte dabei immer auf eine Gruppe identischer Einheiten.

13 Zur Diskussion der Rolle von Fiktion in den Wissenschaften insbesondere am Beispiel des Gedankenexperiments vgl. Macho/Wunschel 2004. Der Begriff der „Fiktion“ wird dort in einem weiten Sinne (von: formen, bilden, gestalten, hervorbringen und vorstellen) verstanden (vgl. Weigel 2004). Krause/Pethes (2005) sprechen von „literarischen Experimentalkulturen", um zu verdeutlichen, dass sich Wissenschaft und Literatur gerade im Konzept der Potentialität und des Möglichkeitsraums treffen, da auch jede naturwissenschaftliche Versuchsanordnung durch ihre auf die Zukunft ausgerichtete Offenheit einen fiktiven Ursprung habe (vgl. ebd.: 17). Für Ansätze, die sich auf die Rolle narrativer Strukturen und ihre identitätsstiftende Funktion in wissenschaftlichen Repräsentationsweisen richten, vgl. Breger/Krüger-Fürhoff/Nusser 2008.

14 „'Fertile' Intestine Nuclei“ (Gurdon /Uehlinger 1966: 1240).

15 Vgl. DiBerardino 1997: 28-67, Kolata 1997, Maienschein 2003, Gurdon 2006.

16 „These results are therefore consistent with any theory of cell differentiation which does not require that the nucleus of a differentiated cell has lost the genetic information required for the formation of other differentiated somatic cell types." (Gurdon 1962: 637)

17 Vgl. dazu DiBerardino 1997: 66f., $75 f$. 
18 Zur Geschichte der Reproduktionsforschung vgl. Clarke 1998. Das Ingenieursideal einer ,neuen' Biologie seit 1900 wird im angelsächsischen Raum zumeist auf den überaus großen Einfluss von Jacques Loeb zurückgeführt (vgl. Pauly 1987).

19 Zum Begriff der Konjunktur als „unvorwegnehmbares Ereignis“ vgl. Rheinberger 2001: 144.

20 Zur Debatte über Illmensee vgl. Kolata 1997.

21 Haldane und die Brüder Julian und Aldous Huxley kannten sich seit ihrer gemeinsamen Jugendzeit in Oxford.

22 Muller verweist im Vorwort darauf, dass das Manuskript in seinen Grundzügen bereits 1925 fertiggestellt war. Seine Veröffentlichung fällt in die Zeit, in der Muller, der in den USA keine Stellenaussichten hatte, in der Sowjetunion arbeitete (vgl. Pauly 1987: 177-189).

23 Haldanes Daedalus beispielsweise erfüllt einen Großteil der genannten Kriterien.

24 Auch hierfür ist Haldanes Daedalus ein gutes Beispiel: Die 1995 veröffentlichte Textsammlung Haldane's Daedalus revistited, in der Biowissenschaftler Haldanes Text in Bezug auf die Situation der 1990er Jahre befragen, ist ein gutes Beispiel für eine derartige Anschlussfähigkeit bzw. Aktualisierungsmöglichkeit (vgl. Dronamraju 1995).

25 In ihrer Geschichte der In-vitro-Fertilisation legt Christine Schreiber die legitimierende Funktion von Muller und Haldane für das Feld der Forschungen zur künstlichen Befruchtung dar, das in den 1920er und 1930er Jahren noch mit gesellschaftlichen Tabus belegt war (vgl. Schreiber 2007: 238-251).

26 Haldane versuchte der tradierten Rezeption des Prometheus-Mythos seinen Daedalus als „ersten modernen Menschen“ (Haldane 1925: 40) entgegenzusetzen. Viel zitiert ist der Satz: „Wenn jede physikalische und chemische Erfindung eine Blasphemie ist, so ist jede biologische Erfindung eine Perversität. Es gibt kaum eine einzige, die nicht, einem Beurteiler aus Kreisen einer über ihre Existenz vorher nicht informierten Nation mitgeteilt, diesem schamlos und naturwidrig erscheinen würde." (Ebd.: 38)

27 Muller bediente sich hier bereits der damals dominant werdenden Schrift- und Informationsmetaphern, indem er Gene mit Wörtern und Nukleotide mit Buchstaben verglich (Muller 1960: 455).

28 Zur Darwin-Gedächtnisfeier 1959 vgl. ausführlich Smocovitis 1999. Smocovitis erläutert, dass Muller vorgeschlagen hatte, Vertreter der noch jungen Molekularbiologie, namentlich Lederberg und Watson einzuladen, was aber aus organisatorischen Gründen scheiterte (ebd: 274f.).

29 Huxleys Hauptargument, das von anderen Evolutionstheoretikern kritisiert wurde, war, dass mit dem Erscheinen des Menschen ein qualitatives neues Stadium in der Evolution erreicht sei: „Der psychosoziale Prozeß - mit anderen Worten, der evoluierende Mensch ist ein neues Evolutionsstadium, eine neue Phase des kosmischen Ablaufs, die sich von der vormenschlichen biologischen Phase ebenso grundlegend unterscheidet wie diese von der anorganischen, präbiologischen. Diese Feststellung hat eine ganz besondere Bedeutung für die Eugenik." (J.Huxley 1965 [1964]: 264, Herv. i. Original) Zur zeitgenössischen Kritik an Huxley vgl. Greene 1990 und Swetlitz 1995.

30 Die englische Fassung des Symposiums wurde bereits 1963 veröffentlicht, eine deutsche Übersetzung 1966, die französische 1968. Zur Rezeption vgl. z. B. Kaufmann 1964.

31 „Was wird dann den Menschen für das Streben nach menschlicher Erfüllung qualifizieren, was den Unterschied von den anderen durch seinen Geist entworfenen Robotern ausmachen?“ (Lederberg 1966a: 299)

32 Lederberg verwies darauf, dass man am Anfang der zukünftigen Entwicklungen zur Verbesserung des Menschen zunächst mit dem Problem der „subhuman hybrids“ konfrontiert werden würde, da es zu Beginn durchaus Fehlschläge der Forschung geben werde (1966b: 11).

33 Toffler 1971 [1970]: 156. Toffler skizzierte, wie das Klonverfahren es dem Menschen ermöglichen würde, „ihre eigene Wiedergeburt mitzuerleben, und die Welt mit Doppelgängern zu bevölkern“. Des Weiteren würde das „Verfahren auch zuverlässige empirische Beweise der uralten Streitfrage liefern, ob Erbeigenschaften oder Umwelteinflüsse entscheidender sind“ (ebd.: 155). 
34 Vgl. Brandt 2007. Ausführliche literaturtheoretische Analysen der Klon-Romane der 1970er Jahre haben Corina Caduff (2004) und Maria Ferreira (2005) vorgelegt.

\section{Literatur}

Anonym, 1966. „Zukunft: Todlos glücklich“, Der Spiegel, 26. Dezember, 80-90.

Anders, Günther, 2002 [1980]. Die Antiquiertheit des Menschen. Bd. 2.: Über die Zerstörung des Lebens im Zeitalter der dritten industriellen Revolution. München: Beck.

Brandt, Christina, 2007. Wissenschaft - Literatur - Öffentlichkeit. Die Bedeutung der Science Fiction in den 1970er Jahren für die öffentliche Debatte zum Klonen. In: Sybilla Nikolow und Arne Schirrmacher, Hg., Wissenschaft und Öffentlichkeit als Ressourcen füreinander. Frankfurt a. M.: Campus, 137-164.

Breger, Claudia/Krüger-Fürhoff, Irmela Marei/Nusser, Tanja, Hg., 2008. Engineering Life. Narrationen vom Menschen in Biomedizin, Kultur und Literatur, Berlin: Kadmos.

Briggs, Robert/King, Thomas, 1952. Transplantation of Living Nuclei from Blastula Cells into Enucleated Frogs' Eggs. Proceedings of the National Academy of Sciences, 38, 455-463.

Bromhall, Derek, 1975. Nuclear Transplantation in the Rabbit Egg. Nature, 258, 719-722.

Cartwright, John/Baker, Brian, 2005. Literature and Science. Social Impact and Interaction. Santa Barbara: ABC-Clio.

Caduff, Corina, 2004. Experiment Klon. In: Thomas Macho und Annette Wunschel, Hg., Science \& Fiction. Über Gedankenexperimente in Wissenschaft, Philosophie und Literatur. Frankfurt: Fischer Taschenbuchverlag, 230-242.

Carlson, Elof Axel, 1995. The Parallel Lives of H. J. Muller and J. B. S. Haldane. Geneticists, Eugenists, and Futurists. In: Krishna R. Dronamraju, Hg., Haldanes's Daedalus Revisited. Oxford: Oxford University Press, 90-101.

Clarke, Adele, 1998. Disciplining Reproduction. Modernity, American Life Sciences and the Problems of Sex. Berkeley: University of California Press.

Collini, Stefan, Hg., 1993. C.P. Snow. The Two Cultures. Cambridge: Cambridge University Press.

Cordle, Daniel, 1999. Postmodern Postures. Literature, Science and the Two Cultures Debate. Aldershot: Ashgate.

DiBerardino, Marie A., 1997. Genomic Potential of Differentiated Cells. New York: Columbia University Press.

Dotzler, Bernhard, 2002. Neuere deutsche Literatur. In: Claudia Benthien und Hans Rudolf Velten, Hg., Germanistik als Kulturwissenschaft. Eine Einführung in neue Theoriekonzepte. Hamburg: Rowohlt, 103-123.

Dronamraju, Krishna R., Hg., 1995. Haldane's Daedalus Revisited. Oxford: Oxford University Press.

Ferreira, Maria Aline Salgueiro Seabra, 2005. I Am the Other. Literary Negotiations of Human Cloning. Westport: Praeger.

Fletcher, Joseph, 1972. New Beginnings in Life. A Theologian's Response. In: Michael P. Hamilton, Hg., The New Genetics and the Future of Man. Grand Rapids, MI: Eerdmans, 78-89.

Green, Martin, 1987 [1964]. Alter und neuer Humanismus. In: Helmut. Kreuzer, Hg., Die zwei Kulturen. Literarische und naturwissenschaftliche Intelligenz. C. P. Snows These in der Diskussion. München: Klett-Cotta, 137-152.

Greene, John C., 1990. The Interaction of Science and World View in Sir Julian Huxley's Evolutionary Biology. Journal of the History of Biology, 23, 39-55.

Gurdon, John, 1962. The Developmental Capacity of Nuclei Taken From Intestinal Epithelium Cells of Feeding Tadpoles. Journal of Embryology and Experimental Morphology, 10, 622-640.

Gurdon, John, 2006. From Nuclear Transfer to Nuclear Reprogramming. The Reversal of Cell Differentiation. Annual Review of Cell and Developmental Biology, 22, 1-22. 
Gurdon, John/Elsdale, Thomas/Fischberg, Michael, 1958. Sexually Mature Individuals of Xenopus laevis from the Transplantation of Single Somatic Nuclei. Nature, 182, 64-65.

Gurdon, John/Laskey, R.A./DeRobertis, E.M./Partington, G.A., 1979. Reprogramming of Transplanted Nuclei in Amphibia. In: J.F. Danielli und M.A. DiBerardino, Hg., Nuclear Transplantation. New York: Academic Press (=International Review of Cytology, 9), 161-177.

Gurdon, John/Uehlinger, Verena, 1966. ,Fertile‘ Intestine Nuclei. Nature, 210, 1240-1241.

Habermas, Jürgen, 1987 [1966]. Technischer Fortschritt und soziale Lebenswelt. In: Helmut. Kreuzer, Hg., Die zwei Kulturen. Literarische und naturwissenschaftliche Intelligenz. C.P. Snows These in der Diskussion. München: Klett-Cotta, 313-327.

Haldane, John Burdon Sanderson, 1925. Daedalus oder Wissenschaft und Zukunft. München: Drei-Masken-Verlag [engl. Original: Daedalus, or Science and the Future. London: K. Paul, Trench, Truber \& Co 1924].

Haldane, John Burdon Sanderson, 1966. Biologische Möglichkeiten für die menschliche Rasse in den nächsten zehntausend Jahren. In: Robert Jungk und Hans-Josef Mundt, Hg., Das umstrittene Experiment. Der Mensch. München: Desch, 367-391.

Hayles, N. Katherine, 1999. How we Became Posthuman. Virtual Bodies in Cybernetics, Literature, and Informatics. Chicago: University of Chicago Press.

Huxley, Aldous, 1963. Literatur und Wissenschaft, München: Piper [engl. Original: Literature and Science. London: Chatto \& Windus 1963].

Huxley, Julian, 1957. New Bottles for New Wine. Essays. London: Chatto \& Windus.

Huxley, Julian, 1965 [1964]. Ich sehe den künftigen Menschen. Natur und neuer Humanismus. München: List [engl. Orginal: Essays of a Humanist. London Chatto \& Windus 1964].

Illmensee, Karl/Hoppe, Peter, 1981. Nuclear Transplantation in Mus musculus. Developmental Potential of Nuclei from Pre-Implantation Embryos. Cell, 23, 9-18.

Jonas, Hans, 1974. Biological Engineering - A Preview. In: Ders., Philosophical Essays. From Ancient Creed to Technological Man. Englewood Cliffs, N.J.: Prentice-Hall.

Jonas, Hans, 1987 [1974]. Laßt uns einen Menschen klonieren. Von der Eugenik zur Gentechnologie. In: Ders., Technik, Medizin und Ethik. Praxis des Prinzips Verantwortung. Frankfurt a. M.: Suhrkamp, 162-203.

Kass, Leon R., 1972. New Beginnings in Life. In: Michael P. Hamilton, Hg., The New Genetics and the Future of Man. Grand Rapids, MI: Eerdmans, 15-63.

Kaufmann, Richard, 1964. Die Menschenmacher. Die Zukunft des Menschen in einer biologisch gesteuerten Welt. Frankfurt a. M.: Fischer.

Kay, Lily, 2000. Who Wrote the Book of Life? A History of the Genetic Code. Stanford: Stanford University Press.

Kevles, Daniel J., 1995. In the Name of Eugenics. Genetics and the Use of Human Heredity. Cambridge, MA: Harvard University Press.

King, Thomas/Briggs, Robert, 1956. Serial Transplantation of Embryonic Nuclei. Cold Spring Harbor Symposia on Qualitative Biology, 21, 271-290.

Kolata, Gina, 1997. Das geklonte Leben. Ein Jahrhundert-Experiment verändert die Zukunft des Menschen. München: Diana-Verlag.

Krause, Marcus/Pethes, Nicolas, 2005. Zwischen Erfahrung und Möglichkeit. Literarische Experimentalkulturen im 19. Jahrhundert. In: Dies., Hg., Literarische Experimentalkulturen. Poetologien des Experiments im 19. Jahrhundert. Würzburg: Königshausen \& Neumann, 7-18.

Kreuzer, Helmut, Hg., 1987 [1968]. Die zwei Kulturen. Literarische und naturwissenschaftliche Intelligenz. C. P. Snows These in der Diskussion. München: Klett-Cotta.

Küchenhoff, W., 1952. J. Rostand. Die Biologie und der Mensch der Zukunft. Bildung und Erziehung, 5, 910.

Lederberg, Joshua, 1966a. Die biologische Zukunft des Menschen. In: Robert Jungk und HansJosef Mundt, Hg., Das umstrittene Experiment. Der Mensch. München: Desch, 292-301.

Lederberg, Joshua, 1966b. Experimental Genetics and Human Evolution. Bulletin of the Atomic Scientists. A Journal of Science and its Public Affairs, 22, 8, 4-11.

Lederberg, Joshua, 1966c. Experimental Genetics and Human Evolution. The American Naturalist, 100, 915, 519-531. 
Lederberg, Joshua, 1970. Genetic Engineering and the Amelioration of Genetic Defect. BioSciences, 20, 1307-1310.

Le Guin, Ursula K., 1980. Neun Leben. In: Dies., Die zwölf Striche der Windrose. München: Nymphenburger Verlagshandlung, 161-201.

Macho, Thomas/Wunschel, Annette, Hg., 2004. Science \& Fiction. Über Gedankenexperimente in Wissenschaft, Philosophie und Literatur. Frankfurt a. M.: Fischer Taschenbuchverlag.

Maienschein, Jane, 2003. Whose View of Life? Embryos, Cloning, and Stem Cells. Cambridge, MA: Harvard University Press.

Muller, Hermann J., 1935. Out of the Night. A Biologist's View of the Future. New York: Vanguard Press.

Muller, Hermann J., 1960. The Guidance of Human Evolution. In: Sol Tax, Hg., Evolution after Darwin. Bd. 2: The Evolution of Man. Mind, Culture, and Society. Chicago: University of Chicago Press, 423-462.

Muller, Hermann J., 1966. Genetischer Fortschritt durch planmäßige Samenwahl. In: Robert Jungk und Hans Josef Mundt, Hg., Das umstrittene Experiment. Der Mensch. München: Desch, 277-291.

Oppenheimer, J. Robert, 1987 [1962]. Über Wissenschaft und Kultur. In: Helmut Kreuzer, Hg., Die zwei Kulturen. Literarische und naturwissenschaftliche Intelligenz. C. P. Snows These in der Diskussion. München: Klett-Cotta, 153-165.

Overhage, Paul, 1967. Experiment Menschheit. Die Steuerung der menschlichen Evolution. Frankfurt a. M.: Knecht.

Pauly, Philip J., 1987. Controlling Life. Jacques Loeb and the Engineering Ideal in Biology. Oxford: Oxford University Press.

Pethes, Nicolas, 2005. Terminal Men. Biotechnological Experimentation and the Reshaping of ,the Human' in Medical Thrillers. New Literary History, 36, 161-185.

Rheinberger, Hans-Jörg, 2001. Experimentalsysteme und epistemische Dinge. Eine Geschichte der Proteinsynthese im Reagenzglas. Göttingen: Wallstein-Verlag.

Rostand, Jean, 1952. Die Biologie und der Mensch der Zukunft. Darmstadt: Holle [frz. Original: La biologie et l'avenir humain].

Schreiber, Christine, 2007. Natürlich künstliche Befruchtung? Eine Geschichte der In-vitro-Fertilisation von 1878 bis 1950. Göttingen: Vandenhoeck \& Ruprecht.

Sargent, Pamela, 1980 [1976]. Die Bio-Bombe. München: Goldmann [amerik. Original: Cloned Lives. Greenwich, CT: Fawcett-Publications 1976].

Snow, Charles P., 1987a [1959]. Die zwei Kulturen, Rede Lecture. In: Helmut Kreuzer, Hg., Die zwei Kulturen. Literarische und naturwissenschaftliche Intelligenz. C. P. Snows These in der Diskussion. München: Klett-Cotta, 19-58.

Snow, Charles P., 1987b [1963]. Ein Nachtrag. In: Helmut Kreuzer, Hg., Die zwei Kulturen. Literarische und naturwissenschaftliche Intelligenz. C. P. Snows These in der Diskussion. München: Klett-Cotta, 59-96.

Smocovitis, Vassiliki Betty, 1999. The 1959 Darwin Centennial Celebration in America. Osiris, $14,272-323$.

Squier, Susan, 1994. Babies in Bottles. Twentieth-Century Visions of Reproductive Technologies. New Brunswick, NJ.: Rutgers University Press.

Stierle, Karlheinz, 2001. Artikel „Fiktion“. In: Karlheinz Barck u.a., Hg., Ästhetische Grundbegriffe. Historisches Wörterbuch in sieben Bänden. Bd. 2. Stuttgart: Metzler, 380-428.

Swetlitz, Marc, 1995. Julian Huxley and the End of Evolution. Journal of the History of Biology, $28,181-217$.

Taylor, Gordon Rattray, 1969 [1968]. Die biologische Zeitbombe. Revolution der modernen Biologie. Frankfurt a. M.: Fischer [3. Aufl., engl. Original: Biological Time Bomb. London: Thames \& Hudson 1968].

Toffler, Alvin, 1971 [1970]. Der Zukunftsschock. München: Scherz-Verlag [3. Aufl., engl. Original: Future Shock. London: Pan books 1970].

Wagner, Friedrich, 1969. Vorwort. In: Ders., Hg., Menschenzüchtung. Das Problem der genetischen Manipulation des Menschen. München: Beck, 7-11.

Weigel, Sigrid, 2004. Das Gedankenexperiment: Nagelprobe auf die ,facultas fingendi' in Wis- 
senschaft und Literatur. In: Thomas Macho und Annette Wunschel, Hg., Science E Fiction. Über Gedankenexperimente in Wissenschaft, Philosophie und Literatur. Frankfurt a. M.: Fischer Taschenbuchverlag, 183-205.

Weingart, Peter, 1984. Eugenic Utopias. Blueprints for the Rationalization of Human Evolution. In: Everett Mendelsohn und Helga Nowotny, Hg., Nineteen Eighty-Four. Science between Utopia and Dystopia. Dordrecht: Reidel, 173-188.

\section{Christina Brandt}

Max-Planck-Institut für Wissenschaftsgeschichte

Boltzmannstr. 22

D-14195 Berlin

E-Mail: brandt@mpiwg-berlin.mpg.de 
